Staa, A. van, Sattoe, J.N.T., Strating, M.M.H. Experiences with and outcomes of two interventions to maximize engagement of chronically ill adolescents during hospital

\begin{tabular}{l|l} 
Postprint & 1.0
\end{tabular}

Version

Journal website $\quad$ http://www.pediatricnursing.org/article/S0882-5963(15)00216-X/fulltext

Pubmed link https://www.ncbi.nlm.nih.gov/pubmed/26199096

DOI 10.1016/j.pedn.2015.05.028

This is a NIVEL certified Post Print, more info at http://www.nivel.eu

\title{
Experiences with and Outcomes of Two Interventions to Maximize Engagement of Chronically Ill Adolescents During Hospital Consultations: A Mixed Methods Study
}

\author{
ANNELOESVAN STAAPHD, MD, RNABJANE N.T.SATTOEMSCABMATHILDE \\ M.H.STRATINGPHDA
}

\section{HighLights}

- Patient-provider communication is critical to improve transition-related outcomes.

- Transition readiness support should focus on adolescents' autonomy and life skills.

- Split-visit consultations are easy to implement and agreeable to parents.

- Individual Transition Plans contribute to more holistic and patient-centered care.

- Pediatric nurses are in a unique position to engage adolescents and parents.

Improving patient-provider communication during hospital consultations is advocated to enhance self-management planning and transition readiness of adolescents with chronic conditions. This longitudinal mixed methods study evaluates the implementation and the outcomes of independent split-visit consultations and individual transition plans by 22 hospital teams participating in the Dutch Action Program 'On Your Own Feet Ahead!'. The interventions raised awareness in adolescents and professionals, improved adolescents' display of independent behaviors and led to more discussions about non-medical issues. Successful implementation required a team-based approach and clear explanation to parents and adolescents. Pediatric nurses played a pivotal role in improving transitional care.

EMERGING ADULTHOOD, THE developmental stage between late adolescence and adulthood, covers the period in which young people start to take primary responsibility for tasks associated with adult life (Arnett, 2000). For adolescents with 
Staa, A. van, Sattoe, J.N.T., Strating, M.M.H. Experiences with and outcomes of two interventions to maximize engagement of chronically ill adolescents during hospital consultations: a mixed methods study. Journal of Pediatric Nursing: 2015, 30(5), 757-775

chronic conditions, this is a challenging time in which they must assume increasingly independent responsibility for the management of the condition, in parallel with the transfer from pediatric to adult care settings (Garvey et al., 2013). Both processes require changes in the relationship between the patient and the healthcare provider. Pediatric and adult medical care systems place different demands and expectations on their patients, and adolescents must learn to become effective partners in their own healthcare communication (Viner, 2008). Effective communication is a critical component of independent self-care skills in emerging adults (AAP et al., 2011) as it may help build positive, trusting relations between professionals and their patients. Good communication is also correlated with better clinical outcomes such as treatment adherence (Dimatteo, 2004; Zolnierek \& Dimatteo, 2009).

Staff attitude, communication, and youth involvement are also essential elements for young people's perception of adolescent-friendly healthcare (Ambresin, Bennett, Patton, Sanci, \& Sawyer, 2013). In their judgment of quality, aspects of trust and respect are rated as most important and adolescents prefer communication directly to them rather than to their parents (Britto et al., 2004). Despite good interactional competence or perceived self-efficacy, adolescents often remain inactive during consultations where parents are present (Pyörälä, 2004; van Staa, Jedeloo, van der Stege and On Your Own Feet Research Group, 2011; van Staa, Jedeloo, van Meeteren and Latour, 2011; van Staa and On Your Own Feet Research Group, 2011; Wassmer et al., 2004). Still, as they gradually grow out of the pediatric environment, they welcome being treated more age-appropriately and as equal partners in care (Dovey-Pearce, Hurrell, May, Walker \& Doherty, 2005; van Staa, Jedeloo, van der Stege et al., 2011; van Staa, Jedeloo, van Meeteren et al., 2011; van Staa and On Your Own Feet Research Group, 2011). Healthcare professionals and parents have an important role here, but both seem to have mixed feelings about active adolescent involvement (Coyne, 2008). This is particularly marked when it comes to confidentiality and the right to decide who is present during consultations. Current guidance about developmentally appropriate care emphasizes the benefits of offering confidential consultations to adolescents without parents present, in which psychosocial assessments can be undertaken (Berlan \& Bravender, 2009; Committee on Adolescence AAP, 2008; Ford, English \& Sigman, 2004). First, young people have the right to have their developing autonomy recognized. In many countries, this is embedded in health laws. In the Netherlands, the Dutch Medical Treatment Act (WGBO; 1995) states that young people aged 16 or over have the right to make their own treatment decisions autonomously, and those between 12 and 15 years are entitled to take decisions with their parents. Second, adolescents place high value on confidentiality and seeing healthcare providers alone (English \& Ford, 2007; Rutishauser, Esslinger, Bond \& Sennhauser, 2003). When explicit assurances of confidentiality are provided to adolescents, they are more likely to seek healthcare, disclose sensitive matters, and return for future visits (Ford, Millstein, HalpernFelsher \& Irwin, 1997), whereas concerns over confidentiality decreases willingness to seek care for sensitive issues and may inhibit communication (Carlisle, Shickle, Cork \& McDonagh, 2006).

Although confidential care with associated psychosocial assessment is important for all adolescents, it is particularly relevant for those with chronic conditions, who generally have poorer psychosocial outcomes and lower social participation rates than healthy peers (Sawyer, Drew, Yeo \& Britto, 2007). Still, there is a gap between 
Staa, A. van, Sattoe, J.N.T., Strating, M.M.H. Experiences with and outcomes of two interventions to maximize engagement of chronically ill adolescents during hospital consultations: a mixed methods study. Journal of Pediatric Nursing: 2015, 30(5), 757-775

chronically ill adolescents' expectations and the opportunities given to them to be seen alone in consultations (Rutishauser et al., 2003; Shaw, Southwood \& McDonagh, 2007b). Only a minority of adolescents reported to have had confidential consultations with their healthcare providers (Duncan, Jekel, O'Connell, Sanci \& Sawyer, 2014; Surís, Akre \& Rutishauser, 2009; van Staa, Jedeloo, van der Stege et al., 2011; van Staa, Jedeloo, van Meeteren et al., 2011; van Staa and On Your Own Feet Research Group, 2011); this is in part explained by parents having mixed feelings about confidentiality (Duncan et al., 2014; Gilbert, Rickert \& Aalsma, 2014; Sasse, Aroni, Sawyer \& Duncan, 2013) and in part by healthcare providers not being aware of legal minor consent guidelines or being concerned about parental reaction to such confidential discussions (Berlan \& Bravender, 2009).

Information provision, transition planning and development of self-management skills are important in preparing for transition to adult care. The need for a service model that supports young people to develop self-management skills and become an autonomous individual is widely recognized (Modi et al., 2012). It should address not only medical management, but also psychosocial functioning and social participation, which are considered integral components of comprehensive adolescent care (Martinez, Carter \& Legato, 2011; Sawyer et al., 2007). The use of comprehensive individual transition plans that regularly monitor the development of autonomy in various life domains has been advocated (Ferris et al., 2015; Reiss \& Gibson, 2002). Most patients in transition do not have such plans (Sawicki, Kelemen \& Weitzman, 2014), however, and their practical application has been rarely evaluated (Gravelle, Paone, Davidson \& Chilvers, 2015; Robertson, McDonagh, Southwood \& Shaw, 2006). In contrast to transition readiness assessments (Moynihan, Saewyc, Whitehouse, Paone \& McPherson, 2015; Sawicki et al., 2011; Wood et al., 2014), which serve primarily as a measurement for healthcare providers, such individual transition plans provide guidelines for action for patients, parents and professionals. To date, few approaches for preparing adolescents for transitioning to self-management and transfer to adult care have been empirically tested (Annunziato et al., 2014). Patient-provider communication content and quality, a critical element of transition readiness, has particularly been under-studied (Monaghan, Hilliard, Sweenie \& Riekert, 2013). Intervention opportunities include developmentallyappropriate styles of clinic visits (including independent consultations) and promoting skills for self-management (Gravelle et al., 2015; Monaghan et al., 2013). The implementation and effects of two such interventions (independent consultations and individual transition plans) in a nation-wide quality improvement program in the Netherlands is the focus of this study.

The aim of this study is twofold: (1) to examine the implementation of, and the experiences with, two transitional care interventions by Dutch hospital-based teams participating in the 'On Your Own Feet Ahead!' Quality Improvement program (2009-2012); and (2) to evaluate the short-term and long-term outcomes of the adolescents and young adults involved.

\section{METHODS}

\section{Setting: The 'On Your Own Feet Ahead!' Quality Improvement Program}

In the Netherlands, transitional care is usually provided on an ad hoc basis - essential elements such as transition protocols, coordinators, and individual transition plans, 
Staa, A. van, Sattoe, J.N.T., Strating, M.M.H. Experiences with and outcomes of two interventions to maximize engagement of chronically ill adolescents during hospital consultations: a mixed methods study. Journal of Pediatric Nursing: 2015, 30(5), 757-775

are largely lacking (van Staa, Eysink Smeets-van de Burgt, van der Stege \& Hilberink, 2010). Professionals, parents and adolescents themselves all agreed that improvement was highly necessary (van Staa, Jedeloo, van Meeteren, \& Latour, 2011). In 2008, the multidimensional Action Program 'On Your Own Feet Ahead!' was launched aiming at improving transitional care arrangements in chronic care provided to adolescents in Dutch hospitals and rehabilitation centers. The Program targeted at improving patient experiences and self-management skills (individual level), patient-family-provider interactions (micro-level), and inter-healthcare team partnerships (mesosystem) from the ecological transition model (Wang, McGrath, \& Watts, 2009).

The Breakthrough Series improvement and implementation strategy was followed (IHI, 2003). The Breakthrough strategy helps organizations close a gap between what is known and what is done by creating a structure (the Quality Improvement Collaborative) in which organizations can easily learn from each other and from recognized experts. Our Action Program was a short-term learning system that brought together multidisciplinary teams from hospitals and rehabilitation clinics all over the Netherlands who volunteered to seek improvement in transitional care. Three rounds (one pilot round and two dissemination rounds) of 10 teams each joined the Program between November 2009 and May 2012. Teams were carefully selected for their intrinsic motivation. Most professionals were not reimbursed for their time investment. In Rounds 2 and 3, teams had to contribute $€ 10,000$ to cover part of the costs of the program. At the start of each round, bottlenecks in transitional care provided by a team were identified, and a specific plan of action was drawn up using a comprehensive model for transitional care delivery reflecting international guidelines for good quality transitional care (AAP et al., 2011). In the course of the one-year program, the teams implemented local interventions with support from consultants from the first step (setting goals) to the final step (evaluating the effects of efforts to improve care) of the program. Co-creation with patients and parents was encouraged. In addition, team members participated in national learning sessions in which team building, collaboration, and dealing with barriers in the local setting were addressed and experts (both professionals and patients) shared their experiences with improving adolescent care. During the course of the program, professionals were supplied with formats, instruments, and descriptions of each intervention. A toolkit with descriptions of suitable and promising interventions was made available on the project's website (www.opeigenbenen.nu).

Of the thirty teams, 8 came from rehabilitation clinics and 22 from hospitals. The rehabilitation teams were not included in this study as their care provision and transition services differ from hospital transitional care services. The hospital-based teams treated diverse patient populations: adolescents with diabetes mellitus type 1 (DM1; $n=11)$, chronic kidney diseases and transplantation $(\mathrm{CKD} ; \mathrm{n}=4)$, juvenile idiopathic arthritis (JIA; $\mathrm{n}=2)$; cystic fibrosis $(\mathrm{CF} ; \mathrm{n}=2)$; congenital urological conditions; HIV; and neuromuscular disorders (NMD; one home ventilation support team). Professionals from both pediatric care (PC) and adult care (AC) were present in most teams, while nurse specialists often played a leading role. In 15 teams $(72.7 \%)$, nurses acted as project leader.

\section{Transitional Care Interventions}

Each team used a combination of several interventions to improve the organization of transitional care and to enhance adolescents' self-management. Table 1 provides 
Staa, A. van, Sattoe, J.N.T., Strating, M.M.H. Experiences with and outcomes of two interventions to maximize engagement of chronically ill adolescents during hospital consultations: a mixed methods study. Journal of Pediatric Nursing: 2015, 30(5), 757-775

an overview of the ten most applied interventions two years after start of the program (T2), aiming at (a) improving the organization of transition and enhancing selfmanagement, and (b) preparing adolescents and their parents for the transition to adult care. An overview of all interventions per team was published elsewhere (Nieboer et al., 2014).

\section{[TABLE 1]}

\section{Design of the Evaluation Study}

The independent evaluation study was designed as a longitudinal, mixed-methods research that monitored both the process and outcomes of the Action Program in adolescents and young adults (further referred to as AYA), their parents, and healthcare providers. The study was based on the chain of action evaluation model (Cretin, Shortell, \& Keeler, 2004), developed to assesses the effectiveness of Quality Improvement collaboratives. At the start of the program the general consensus was that improvement of transitional care was desirable (Sonneveld, Strating, van Staa \& Nieboer, 2013). AYA and parents indicated that the care process offered most room for improvement. Providers also reported shortcomings, especially with respect to transition guidelines, protocols and coordination of the transfer. In addition, providers reported that many adolescents did not yet carry responsibility for their own care.

For the process evaluation, interviews with professionals of the participating teams were held in the first year after they completed the program. Furthermore, process indicators on the implementation of the two interventions recorded by the teams were analyzed. These data have not been published before.

For the effect evaluation, a longitudinal design measuring the healthcare experiences, preferences, and self-management competencies (including self-efficacy) of all AYA cared for by the teams on three occasions: start of the program (T0), after one year (at completion; T1), and two years after the start (T2). A first glance at the effectiveness of the Action Program in reducing bottlenecks and improving patient experiences with care delivery, as perceived by AYA and professionals, was published in 2014 (Nieboer et al., 2014).

The current study evaluates the process of the implementation of two interventions in 22 hospital-based teams and links the effects to outcomes. It involves professionals working and AYA treated in these settings (Figure 1).

\section{[FIGURE 1]}

\section{Sample \& Ethics}

The study protocol was approved by the Medical Ethics Committee of Erasmus University Medical Centre, Rotterdam and all participants provided informed consent for their participation in all parts of the study.

\section{Qualitative Study: Process Evaluation}

Sample and Participants 
Staa, A. van, Sattoe, J.N.T., Strating, M.M.H. Experiences with and outcomes of two interventions to maximize engagement of chronically ill adolescents during hospital consultations: a mixed methods study. Journal of Pediatric Nursing: 2015, 30(5), 757-775

We aimed to include all hospital-based teams that had participated in the Action Program. From each team, at least two professionals were targeted to be interviewed in the first year after completing the program, including the project leader. The semistructured face-to-face interviews were administered by trained Bachelor and Master students from the Erasmus University Rotterdam, supervised by AvS and MS, or by Bachelor of Nursing students from Rotterdam University of Applied Sciences, supervised by JS. Interviews lasted about 40-70 minutes and were audio-recorded and subsequently transcribed verbatim.

\section{Interview Guide}

The interview guide, designed by the research team based on previous qualitative research (van Staa and On Your Own Feet Research Group, 2011; van Staa et al., 2011a; van Staa et al., 2011b) focused on the overall experience with adolescent care and the Action Program and more specifically with the transitional care interventions and reasons for (not) selecting them.

\section{Data-Analysis}

The qualitative analysis was performed by the research team. All interview transcripts were imported into the qualitative software package ATLAS.ti 6.2 (www.atlasti.com) and analyzed using a method of qualitative content analysis (Elo \& Kyngäs, 2008). A first coding frame, developed on the basis of the interview guide, was continuously modified and expanded as new themes emerged during the analysis.

\section{Process Indicators}

All teams participating in Round 3 collected process data on central indicators measuring the progress in the implementation of the two interventions. In an Excel database, teams recorded for every consultation with adolescents over 12 whether they had been seen independently and whether an ITP had been drafted.

\section{Quantitative Study: Effect Evaluation}

\section{Sample and Participants}

The effect evaluation among AYA was performed through a longitudinal questionnaire study. Inclusion criteria were: age 11-25 years, no history of a mental disorder, and receipt of pediatric care or treatment at T0; the total sample was 1,073 at T0; and 1,046 at T1. At T1 and T2, they completed the same questionnaire administered at T0. Nine teams had reached the end-point of the study before T2 and therefore the T2 sample included no more than 660 AYA.

\section{Data Collection}

AYA received a letter asking them to complete a questionnaire. A reminder was sent to non-respondents two weeks later. A small financial incentive of $€ 10$ was offered to stimulate participation.

\section{Measures}

Items of all measures are presented in Supplementary file A. 
Staa, A. van, Sattoe, J.N.T., Strating, M.M.H. Experiences with and outcomes of two interventions to maximize engagement of chronically ill adolescents during hospital consultations: a mixed methods study. Journal of Pediatric Nursing: 2015, 30(5), 757-775

I. The Independent Behaviors During Consultations Scale (IBDCS) was used to measure the self-reported frequency of several independent behaviors (van Staa \& Sattoe, 2014). The scale consists of 7 items scored on a Likert scale ranging from $1=$ never to $5=$ always. Cronbach's alpha $(\alpha)=.79$.

II. AYA further rated their General independence during consultations with a score between 1 and 10; a higher score indicated more self-reported independence.

III. Topics Discussed During Consultations Scale (TDDCS): this self-constructed scale consists of two subscales, assessing A) how often topics related to nonmedical issues are discussed during hospital consultations, and B) the importance attached by AYA to discussing these topics. Each subscale consists of 5 items and asks about discussions concerning the transfer to adult care, sexuality, intimate relations and fertility, education and employment, and the future prospects of the condition. Items are rated on a 5-point Likert scale ranging from $1=$ never to $5=$ always; or $1=$ not important at all to $5=$ very important. Internal consistency was not calculated due to different content of the items.

IV. The Dutch version of the 10-item General Self-Efficacy Scale (GSES) (Schwarzer \& Jerusalem, 1995) served to assess optimistic self-beliefs. Responses are structured on a four-point scale: $1=$ not at all true; $2=$ hardly true; 3 = moderately true; and $4=$ exactly true. A total score $(10-40)$ is obtained by summing the responses to each of the 10 items; $\alpha$ in this study was 0.85 .

V. Condition-related self-efficacy was measured with two subscales of the $O n$ Your Own Feet Self-Efficacy Scale (OYOF-SES) (van Staa, 2012): A) Selfefficacy in knowledge of the condition (7 items; $\alpha=.81$ ); and B) Selfefficacy in skills for independent hospital visits ( 6 items; $\alpha=.88)$. All questions are scores on a 4 -point Likert scale $(1=$ no, certainly not; $2=$ no, probably not; $3=$ yes, probably; 4 = yes, certainly). The OYOF-SES represents participants' perceptions of their confidence to self-manage their symptoms and regimen and their relations with healthcare providers during consultations.

VI. Satisfaction with current care provision was investigated with the 'Mind the GAP' scale (Shaw, Southwood \& McDonagh, 2007a). The original instrument consists of 22 items, with responses structured by a seven-point Likert scale ranging from 1 (strongly disagree) to 7 (strongly agree). Respondents are asked to rate the items for their expectations of the "best" care and to rate the "current" care. In this study, we selected 6 "current" care items, which are linked to expected changes in the quality of care delivery brought about by the two selected interventions. Three items from the original sub-scale 'provider characteristics' relate to ICs; while three others (two from the sub-scale 'process issues' and one self-constructed item) could be linked to the use of ITPs.

Statistical Analysis

All statistical analyses were conducted with SPSS software (22.0; IBM). We used descriptive statistics. Changes in the measurements over time (between T0-T1 and between T1-T2) were tested with two-tailed, paired sample T-tests and Wilcoxon Matched Pair Signed Rank tests. 
Staa, A. van, Sattoe, J.N.T., Strating, M.M.H. Experiences with and outcomes of two interventions to maximize engagement of chronically ill adolescents during hospital consultations: a mixed methods study. Journal of Pediatric Nursing: 2015, 30(5), 757-775

\section{RESULTS}

\section{Interviews: Participants and Response}

Of all hospital-based teams 18 participated in the interview study (81.8\%). One team's progress was seriously delayed due to changes in personnel and this team was not invited to participate. Three teams did not consent to be interviewed; the major reason was time constraint.

A total of 37 healthcare professionals were interviewed (Table 2). There was a predominance of specialized nurses working in PC, and other interviewees were pediatricians, social workers, a medical specialist and one manager. Of all respondents, 29 worked in PC (78\%), seven in AC and one in both settings. Fifteen of the interviewees were project leaders (12 nurses and 3 doctors).

\section{[TABLE 2]}

\section{Independent Consultations}

Professionals' ideas about and experiences with ICs in their daily routines were discussed. This intervention was particularly popular in diabetes care $(9 / 11$ teams were adopters), in total 14 teams promoted ICs actively as standard policy. Here, we present experiences of both adopting and non-adopting teams. We describe how the intervention was put into practice in different settings, reasons were for adopting or not adopting ICs, and how rationales for this decision were communicated to parents and adolescents. Professionals also discussed possible advantages and disadvantages of the intervention (summarized in Table 3).

\section{[TABLE 3]}

\section{ICs in Practice}

There was some variation in the way ICs were implemented: most teams adopted a strategy of split-visits (Gilbert et al., 2014) in which the consultation starts with the adolescent alone, after which parents are invited to join and the adolescent summarizes the conversation so far. Parents are then given the opportunity to voice concerns or ask questions. Some teams decided not to communicate directly with the parents anymore in routine consultations, while others changed the number of people present per consultation: while a nurse saw the adolescent alone, the social worker talked to the parents, followed by the doctor seeing them together.

\section{Reasons for Adopting ICs/Advantages}

Building adolescents' transition capacity was the most important reason for applying this intervention. This theme recurred in all interviews with adopters. Several respondents indicated that the Action Program had raised their awareness about the importance of fostering young people's independence: "We are now more alert to encourage independence wherever we can" (Nurse PC-DM1-\#28). ${ }^{1}$ ICs help to activate adolescents and "encourage the development of young people's skills, because they learn how to manage the communication and to indicate what the problem is" (Nurse PC-CF-\#11); they are invited "to take increased responsibility for their own self-care" (Nurse AC-DM1-\#29); and "not leave everything to Mum and Dad ... when they're 15 or 16 years old" (Doctor PC-DM1-\#29). Seeing adolescents 
Staa, A. van, Sattoe, J.N.T., Strating, M.M.H. Experiences with and outcomes of two interventions to maximize engagement of chronically ill adolescents during hospital consultations: a mixed methods study. Journal of Pediatric Nursing: 2015, 30(5), 757-775

alone for part of the consultation "is not coincidental like before, but part of a master plan of our entire team to teach adolescents how to manage their affairs during consultations, since this is expected of them in adult care" (Doctor PC-DM1-\#5). The intervention is seen as essential for preparing the transfer and seeing adolescents alone in the trusted pediatric environment is helpful: "adolescents should not share their health and other problems only with their parents, but also with healthcare providers. So we practice this in a trusted setting, with people they trust - later they'll have to do it with others they don't know that well' (Nurse PC-AC-CKD\#19).

Due to the Dutch law granting AYA over the age of 16 the right to decide by themselves, ICs are offered to older adolescents, but some stated that ICs are also suitable for younger adolescents:

The Action Program really has made us more aware of the importance of confidential consultations. The conversation proceeds quite differently when we see them on their own. They are more involved and have no opportunity to check their phones. You make them feel more responsible for their diabetes. At the end of the consultation, we invite the parents in if they're still in the waiting room. Then the adolescent explains what has been discussed. We are so positive we decided to do it more often, even with younger kids. Doctor PC-DM1-\#26

Team members from AC had often encouraged their pediatric colleagues to implement the intervention:

We had expected that PC professionals would foster the idea of developing independence, but we noticed that they really nanny these adolescents. So we said this absolutely had to change before the gap between pediatric care and internal medicine could be bridged. They are too much on top of the kids and do not offer room for things children themselves wish to discuss. So we promoted ICs. Nurse ACDM1-\#27

In one case, however, the adult team had advised against the intervention, whereas the pediatric team voted in favor: "They questioned whether it was really necessary; they felt that things were going OK now. So we rested our case." (Nurse PC-NMD\#4).

Only one nurse stated that confidentiality, which is indispensable when risk behaviors or sensitive issues are discussed, was an important reason to implement the intervention: "We often invite the young person to come alone, because that's necessary to discuss private issues such as sexual health. So they know they are always welcome to come on their own" (Nurse PC-DM1-\#28). Still, many respondents saw confidentiality as an important advantage of ICs: "Especially when they want to discuss things that their parents are not supposed to know, such as drinking or smoking, then they really like it." (Nurse PC-JIA-\#3). A CF team saw the intervention as part of their strategy to address adherence, because "we expect adolescents to talk more freely about their medication adherence without their parents around" (Doctor PC-CF-\#11).

Another advantage of the intervention was the positive feedback professionals received from young people themselves: "I think patients really like to take more responsibility. When they are alone in the consultation room, even the most nontalkative, stubborn teenager starts talking" (Doctor PC-CF-11). A nurse commented: "Young people like it and we see that almost all of them are now coming on their own when we have the transition clinic" (Nurse AC-JIA-\#3). Also parents come to 
Staa, A. van, Sattoe, J.N.T., Strating, M.M.H. Experiences with and outcomes of two interventions to maximize engagement of chronically ill adolescents during hospital consultations: a mixed methods study. Journal of Pediatric Nursing: 2015, 30(5), 757-775

appreciate ICs because they not feel excluded, while it could be hard to convince parents to step back and cede control to their child, it is necessary to encourage selfreliance. Like others, this nurse stressed that it would not do to exclude parents when complications or medical setbacks occur, but when things go back to normal, the adolescent should take over again. Therefore, clearly explaining the reasons for ICs to parents and adolescents is essential: "Resistance quickly resolves when you explain it well and after they've experienced it once" (Doctor PC-DM1-\#26).

\section{Making it Standard Policy or Not}

There is some controversy between the respondents as to how "strict" the intervention should be implemented. Most made it standard policy for routine consultations, while others who were reluctant to "force" parents and adolescents into this procedure pleaded for "freedom of choice". A nurse in diabetes care felt it worked best to make it standard policy:

This is the way we work here - we explain to everyone why we do it this way. We do it for a good reason. The advantage [of a standard policy] is that you do not have to discuss it every time with the teenager or the parents. It is the same with our joint medical consultations. If you leave teenagers too much room to decide, they will all say NOOOOO, so they need some extra stimulus - and then they'll do it and even like it. Nurse PC-DM1-\#12

Other respondents feel that there is no one-size-that-fits-all and stressed that flexibility is needed while keeping the ultimate goals in mind. Parent exclusion from everyday care is unwanted, so "when there are serious problems with adherence, you need parents in the consultation room" (Nurse PC-DM1-\#28), although others felt that this will only increase conflict.

Reasons for not adopting and reported disadvantages of ICs are mostly related to reluctance to exclude parents. Non-adopting teams preferred to leave the decision with the parents and the adolescents themselves. They feel it would be wrong to interfere:

We have decided to leave it the way it is. Only if we notice that children have something on their mind will we discuss it in our team meeting and do we decide to invite children to come without their parents. That is difficult, yes. Nurse PC-JIA-\#17 In conclusion, adopters were very positive about seeing adolescents alone for part of the consultation as part of the strategy to enhance transition readiness. They saw more advantages than disadvantages, but warned against excluding parents from care and pleaded for flexibility. The non-adopters felt that patients and parents themselves should decide on this issue and stressed the importance of parents as source of support and as partner in care.

\section{Individual Transition Plans}

Professionals' ideas about and experiences with ITPs were discussed. In total 16 teams implemented this intervention, i.e. all CKD and JIA teams, and 8 of 11 DM1 teams. We describe how the intervention was evaluated and put into practice in different settings. Professionals also discussed possible advantages and disadvantages as well as reasons for (not) adopting the intervention. Table 4 summarizes the key themes. 
Staa, A. van, Sattoe, J.N.T., Strating, M.M.H. Experiences with and outcomes of two interventions to maximize engagement of chronically ill adolescents during hospital consultations: a mixed methods study. Journal of Pediatric Nursing: 2015, 30(5), 757-775

\section{[TABLE 4]}

\section{Developing the Instruments ITP and SGU-N}

In the Action program, new instruments were developed aimed at promoting development of autonomy in all life areas, not just healthcare, and stimulating young people and their parents to take action. The Basic ITP was drafted in the first Round after consultation of international examples available on the internet in 2007, such as the 'Growing Up and Moving On' program (Robertson et al., 2006) and 'On TRAC' (Paone, Wigle \& Saewyc, 2006). The general lay-out and composition of the overall domains were decided on in three separate expert meetings with parents, young adults and healthcare professionals. Most teams used one general ITP for all ages between 12 and 18, some adopted a format with three separate, developmentallyappropriate forms: for use in early $(12-14 \mathrm{yr})$, middle $(14-16 \mathrm{yr})$, and late $(17+)$ adolescence. Teams were encouraged to adapt the Basic ITP to their local settings; generic items were usually adjusted to reflect the chronic condition treated. Together with the nephrology teams we developed a different kind of ITP, the Skills for Growing Up-Nephrology (SGU-N) (Sattoe, Hilberink, Peeters \& van Staa, 2014). The SGU-N also encourages typical development towards independence and autonomy in nine life areas: 'me', 'healthcare', 'relationships', 'education', 'work', 'living and ADL', 'transportation', 'leisure activities', and 'sports'. It consists of three age-appropriate lists (7-11 years: 'Getting started'; 12-16 years: 'On my way'; 17 years and older: 'Almost there'). Supplementary file B presents the domains of both instruments. The SGU-N contains more items per domain than the Basic ITP. Both instruments had separate versions for parents and the youth.

\section{Working with ITPs in Practice}

Most teams acted as follows: in the case of an ITP for an adolescent (aged 12+), both the child and the parents were asked to rate the adolescent's independence and to select items for discussion and action. Usually the forms were sent out before the consultation, or alternatively presented in the waiting room. In most teams, pediatric nurses discussed the ITP/SGU-N with the adolescent and parents together. Other teams assigned domains to different team members, e.g. school and work to a social worker, and the healthcare domain to the nurse and doctor. Items discussed were recorded in the patient file; usually in the form of a checklist in which these items were ticked. ITPs are updated yearly, but the relevant items are brought up in every patient encounter. Furthermore, developmental issues from the ITP are discussed in multidisciplinary team meetings. A minority of teams also transferred adolescents' ITP to AC after consent ("the job is not yet done after transfer" Nurse AC-CF-\#11); but most used it only in $\mathrm{PC}$, documenting in the patient referral letter for the $\mathrm{AC}$ provider the areas that still needed to be addressed.

Most respondents viewed the ITP as a communicational tool: "It is an instrument to find out from adolescents and parents what occupies their minds" (Nurse PC-CF\#11). The ITP serves the purpose of identifying gaps in knowledge and skills in the development of autonomy. It encourages adolescents to identify specific issues they wish to work on: "We do not ask young people 'which items would you like to work on', because then they'll all say: 'none'. Together we'll select three areas to work on in the coming year" (Nurse PC-CF-\#11). The information from ITPs is used to designate specific goals for patient education. Information from ITPs is often shared between professionals to prepare for consultations. "The ITP provides clear leads: is 
Staa, A. van, Sattoe, J.N.T., Strating, M.M.H. Experiences with and outcomes of two interventions to maximize engagement of chronically ill adolescents during hospital consultations: a mixed methods study. Journal of Pediatric Nursing: 2015, 30(5), 757-775

this child ready for transfer or does he or she still need to work on certain subjects; do we need to educate" (Doctor PC-DM1-\#27). Nurses and doctors felt responsible for addressing all items over time and put the information in their records so that they could tailor their care to individual needs: "The ITP serves as a tool to provide guidance on how to tailor the content of your consultations" (Nurse AC-DM1-\#21). Some nurses had implemented an electronic checklist, so that topics addressed could easily be checked after transfer; others used the information to prepare for the transition clinic: "We let the AC team know what the patient's specific areas of concern are and what they will have to work on. Ideally they continue working with these, and that's recommended, until the age of 24-25" (Nurse-PC-DM1-27).

\section{Empowerment or Assessment?}

Respondents had different ideas about 'ownership' of the ITP. Some saw it as a means to empower the young person: "patients own it, they decide about recording the items and transferring the ITP to AC" (Nurse AC-CF-\#11); others felt it was primarily intended to be of benefit to the healthcare team. Nevertheless, both factions seemed to agree that the tool helped to make their care more patient-centered: "Working with ITPs has made my consultations with children so much more fun: we now talk about living a life with diabetes, not just about the HbA1c" (Nurse PCDM1-21).

\section{Advantages of Using ITPs}

The respondents named two major advantages of applying ITPs.First, creating awareness in all parties involved. For example in parents: "It raises awareness: parents need to realize that the child must become independent and that they must cede control to their kids" (Nurse AC-CF-\#11). But also in children, if "it appears that they do not actually know what the condition entails" (Nurse PC-JIA-17). Using ITPs also enlightened healthcare professionals about the need to provide holistic, comprehensive care and it brings issues to the fore that used to remain in the dark: The first ITP conversation focuses on the disease and the medication itself; I do not have time to address the other topics. [The ITP] touches upon so many things: whether children are being bullied, that they would like to play soccer while their parents would not let them. There are lots of items that I cannot discuss ... Well; these must be left for the next time. Nurse PC-JIA-\#17

Second, use of the ITP stimulates family interaction:

There was a girl who never did any household chores. This became clear from both ITPs and the parents wondered: 'where do we start?' So we made a plan and now she's doing a little cooking and shopping herself. I really love that! Without the ITP, we would never have guessed this because there would be a greater focus on the disease alone. But these developmental issues, they are really part of care. Social worker PC-CKD-\#19

\section{Disadvantages of ITPs}

Working with ITPs was not all fun, however. Many respondents complained about red tape and of complex logistics: "It's a lot of paper work and we don't know who should keep the ITP or to store it" (Nurse PC-CKD-22). Also, while there was a general preference for working with developmentally-appropriate ITPs, this increased the amount of paper work. The inflexibility of the paper version and the demanding logistics caused one team to drop working with the ITP as a paper tool, while claiming that they had integrated this way of working into their regular 
Staa, A. van, Sattoe, J.N.T., Strating, M.M.H. Experiences with and outcomes of two interventions to maximize engagement of chronically ill adolescents during hospital consultations: a mixed methods study. Journal of Pediatric Nursing: 2015, 30(5), 757-775

\section{(1)}

consultations: Even though we do not work with the paper version anymore, our discussions with patients and parents have undergone a complete shift now. We never used to talk about role-changes between parents and child; we did not stimulate the young people to do things themselves. (Nurse PC-NMD-\#4).

To overcome the limitations of a paper format, the CKD-teams decided to build the SGU-N into KLIK, a safe web-based application to monitor pediatric patient reported outcomes in the Netherlands (Haverman et al., 2013). Patients and parents can fill out the online forms at home, while professionals can read the results directly on their screens (Sattoe et al., 2014).

Another disadvantage is that ITPs contain self-reported data. Fearing "socially desirable answers and classifying people in a certain manner" (Nurse PC-CF-\#6), one team declined working with ITPs. In contrast, according to a doctor, a serious risk is that professionals start using these forms as measurements while ignoring discussing the outcomes during consultations:

[The ITP] should be used as a means to achieve something, not as a goal in itself. That is the disadvantage of surveys: people grow tired of them. So you really should discuss the issues during consultations. Doctor AC-JIA-017

This implies that professionals must know how to interpret the results. A nurse felt unsure "how to read the ITP and translate it into actions" (Nurse PC-DM1-\#27). Several participants stated that people are tired of surveys and that this is a serious limitation of ITPs. Its length was also indicated as problematic by some, although several nurses reported that while parents complained about the length, adolescents finished the task rather quickly: "Parents took much more time than the kids; those were finished in no time" (Nurse PC-DM1-12).

In conclusion, teams that took up working with ITPs liked that this tool enabled them to discuss developmental and psychosocial topics in a more structured way. They also appreciated that ITPs stimulate family interaction and that it puts the adolescents in the lead to work towards more autonomy. On the downside were the increase of paper work and the pen-and-paper mode of administration causing logistic and time problems.

\section{Process Indicators}

Figures 2 and 3 present the overall process data of 7 hospital teams (4 diabetes teams and 3 nephrology teams) from Round 3 that adopted both interventions. Figure 2 shows that ICs were implemented early with a steady increase over time. Since the intervention was often only implemented in AYA over the age of 16, not all consultations were organized as ICs. Data from the same teams about the use of ITPs in Figure 3 demonstrates that the uptake of this intervention was slower.

\section{[FIGURE 3] [FIGURE 4]}

\section{Effect Evaluation Among Adolescents and Young Adults}

\section{Questionnaires: Participants and Response}

Out of 22 hospital-based teams, $19(86.4 \%)$ participated in the questionnaire study among AYA. Two teams from Round 1 declined participation, one because of interference with other studies running at the same time and the other due to serious delay in the implementation of the interventions. One non-participating team was also not represented in the qualitative study. T0 and $\mathrm{T} 1$ measurements were 
Staa, A. van, Sattoe, J.N.T., Strating, M.M.H. Experiences with and outcomes of two interventions to maximize engagement of chronically ill adolescents during hospital consultations: a mixed methods study. Journal of Pediatric Nursing: 2015, 30(5), 757-775

completed in all 20 teams, while the T2 measurement could not be performed in 9 teams from Round 3 to earlier having reached the end-point of the study. Response rates varied per measurement moment: $\mathrm{n}=389(36.3 \%$; range $17.4-60.0)$ at $\mathrm{T} 0 ; \mathrm{n}=430$ (41.1\%; range 13.3-55.2) at $\mathrm{T} 2$; and $\mathrm{n}=207$ (31.4\%; range 25.0-34.8) at T2. Figure 4 presents an overview of the response per measurement and the matches between T0-T1 $(\mathrm{n}=250)$ and T1-T2 $(\mathrm{n}=149)$.

\section{[FIGURE 4]}

Characteristics of the respondents at the three measurements are presented in Table 3. Age at T0 ranged from 11-25 years (mean 16.1; SD 2.3). There were more female than male respondents, most AYA reported having no physical limitations, and over $80 \%$ had received their diagnosis after the age of six. The majority of AYA were diagnosed with DM1 or JIA. At T1, a quarter of the respondents had moved to $\mathrm{AC}$; at $\mathrm{T} 2$ this was $46.6 \%$.

Regarding ICs, outcomes confirm that these exert some positive effects.

Improvements in the self-reported independent behaviors (IBDCS) and self-efficacy (OYOF-SES) during consultations were already apparent at the end of the Action Program $(\mathrm{T} 1 ; p<.001)$ and further improved two years after the start $(\mathrm{T} 2 ; p<.01)$. General self-efficacy (GSES) and general independence scores also increased. When looking at the specific items of the IBDCS (Table 4); independent behaviors such as attending the consultation on your own, participating in treatment discussions, asking questions, and discussing private matters all showed a marked score increase (T2; $p<.001)$.

Also, rating of the quality of current care provided further proof of an actual change in the care processes. Table 6 shows that AYA valued the increased opportunities to be seen alone. This was already apparent at T1 and scores further increased at T2 up to a mean of $6.2(\mathrm{SD}=1.1$ ) out of a maximum of 7 (strongly agree). Over time, AYA also indicated that they had more choice to decide who will be present and showed more confidence in talking about sensitive issues with staff. (See Table 5.)

\section{[TABLE 5][TABLE 6]}

Regarding the implementation of ITPs, the data from the effect evaluation also indicate improvement. According to adolescents, their services are increasingly helping them to prepare for their transfer to $\mathrm{AC}$, to plan their future and to enhance their independence through the use of action plans (Table 6). These improvements were apparent at T2 only, indicating that it takes longer for ITPs to be implemented and for adolescents to value them.

The use of ITPs also implied a shift in the topics discussed during consultations. Figure 5 presents adolescents' report of the frequencies of discussions about nonmedical issues on a scale of 1 to 5. In all areas, adolescents reported a higher frequency of discussions on education and employment, intimate relationship and fertility, and the transition to AC. This was increasingly found important, too, over time. Scores on the importance of discussing sexuality-related issues, the future prospects of the condition and the transition to $\mathrm{AC}$ increased the most between $\mathrm{T} 1$ and T2 (Figure 6). A comparison of the valuation of the importance of discussions with the actually reported frequencies (gap scores calculated by subtracting the mean scores at T2 for 'frequency' from 'importance') indicates that there is still further 
Staa, A. van, Sattoe, J.N.T., Strating, M.M.H. Experiences with and outcomes of two interventions to maximize engagement of chronically ill adolescents during hospital consultations: a mixed methods study. Journal of Pediatric Nursing: 2015, 30(5), 757-775

room for improvement: particularly related to intimate relations and fertility (gap score $=1.2$ ); future prospects of the condition (1.4), and transition to AC (1.3).

\section{[FIGURE 5][FIGURE 6]}

\section{Discussion}

This study evaluated a large national Quality Improvement Collaborative (The Action Program 'On Your Own Feet Ahead!') aimed at improving medical transitional services in the Netherlands. The focus of this study was on the experiences with and outcomes of two interventions directly aiming at adolescentprovider communication. The Quality Improvement approach suits the challenges of providing complex, multidisciplinary care to the highly vulnerable population of young people with chronic conditions and has been successfully applied earlier in transition care (McManus et al., 2015). Our approach covered most of the "Six Core Elements of Health Care Transition" (www.gottransition.org), i.e. working on policy, patient tracking, transition readiness, planning, transfer, and completion of the transition. In our experience, intensive collaboration of adult and pediatric providers, designing a transition clinical pathway, applying a multidimensional framework based on a broad holistic approach of self-management, and implementing practical interventions were crucial factors, as was demonstrated in other evaluations (Gravelle et al., 2015).

We provide a strong case for focusing on more patient-centered and holistic communication with adolescents. While this idea has received wide recognition (American Academy of Pediatrics et al., 2011), very few studies have actually documented what happens in practice and what interventions bring about (Monaghan et al., 2013). Also, engaging adolescents as primary partners in their own healthcare may meet with resistance from parents who are concerned about being excluded from care (Duncan et al., 2014) and from healthcare professionals who feel insecure about how best to enact adolescent-friendly care in the chronic-illness outpatient setting. Parental involvement is indeed undisputed by adolescents and professionals alike (van Staa \& On Your Own Feet Research Group, 2011), even more so in chronic care than in other areas of adolescent health. In a qualitative study, adolescents with chronic conditions were more interested in involving parents in their care than those without (Klostermann, Slap, Nebrig, Tivorsak, \& Britto, 2005). Healthcare providers in our study confirmed that the provision of confidential care to young people does not necessarily preclude parental involvement.

The introduction of a split-visit confidentiality model for consultations in our study, as advocated by (Gilbert et al., 2014) for preventive care, resulted in clinical conversations that addressed more topics and increased adolescents' involvement and independent behaviors. This arrangement appealed to professionals, who felt they had better communication with adolescents, as well as to adolescents -who appreciated the opportunity of talking to the provider on their own- while it also provided an inclusive environment for parents. All adopting teams reported that this intervention was easy and quick to implement and that is was relatively simple and effective. Important preconditions were a team-based approach and policy, clear communication to parents and adolescents alike, explaining why and when independent consultations are an essential part of a transition clinical pathway. The split-visit model acknowledges the importance of parental involvement and 
Staa, A. van, Sattoe, J.N.T., Strating, M.M.H. Experiences with and outcomes of two interventions to maximize engagement of chronically ill adolescents during hospital consultations: a mixed methods study. Journal of Pediatric Nursing: 2015, 30(5), 757-775

monitoring with adolescents, encourages and facilitates communication, and delivers tailored parental guidance while also respecting adolescents' preferences for confidential healthcare (Ford, Davenport, Meier \& McRee, 2011).

Encouraging self-reliance and empowering young people in addition to engaging parents was also the goal of the second intervention evaluated in this study: the use of Individual Transition Plans (ITPs). Shared management begins with developing a therapeutic alliance between families and providers and ends with an independent, healthy functioning adult (Kieckhefer \& Trahms, 2000). Experiences in our study with the introduction of such plans were predominantly positive, although there were problems with logistics and the intervention was seen as time-consuming. Still, according to adolescents, over time there was indeed a shift to more non-medical topics. The most important advantage was that such self-management action plans served as a conversational tool to open up triadic discussions about developmental tasks and challenges. It made parents, adolescents and professionals more aware of the impact of the condition on all life domains, the need for structured planning of independence development and encouraged talking about social functioning and participation - vital aspects of adolescent health (Sawyer et al., 2007).

The use of these ITPs served the goal of empowering the adolescent to become a partner in healthcare. It encourages the adolescent to set priorities for independence and competency building. This approach seems to divert from the current hype to propagate the use of Transition Readiness Assessments such as TRAQ (Sawicki et al., 2011; Zhang, Ho \& Kennedy, 2014). In these assessment, the focus seems to lie on measurement, psychometric properties and detecting gaps between self-care beliefs, skills and transition planning (Sawicki et al., 2014). Moreover, these instruments are predominantly concerned with medical self-management tasks, but tend to ignore the wider challenges in social participation. While we do not deny the importance of measurements and detecting mismatches, we feel that positive youth engagement is even more important in view of the high risk of discontinuity of care in the transitional period (Downing et al., 2013; Garvey et al., 2013). While a final assessment of readiness skills could be important for planning the transfer, we still need to start early with paying attention to developing life skills, self-management and self-advocacy (Sawyer, 2002). Since the transfer to adult care is but a small part of the much broader transition to adult life, a well-planned transition process should allow young people to reach their full potential. The use of patient reported outcomes such as transition plans could contribute to this goal, as long as these outcomes are not only collected, but also discussed (Haverman et al., 2013).

This raises the question: does talking help to improve outcomes? Our study concluded that adolescents showed more independent behaviors during consultations, but as these data are self-reported it cannot be taken for granted that this is really so. However, other studies also indicated the value of frequent discussions about transition-related issues and the importance of self-reported independence during consultations: these two factors were stronger predictors for transfer readiness than age (van Staa, van der Stege, Jedeloo, Moll, \& Hilberink, 2011). Other studies also confirmed that good preparation appealed to the adolescents (Surís, Rutishauser \& Akre, 2015; van Staa \& Sattoe, 2014), in line with what adolescents themselves tell about their experiences (Betz, Lobo, Nehring \& Bui, 2013; Fegran, Hall, Uhrenfeldt, Aagaard \& Ludvigsen, 2014). 
Staa, A. van, Sattoe, J.N.T., Strating, M.M.H. Experiences with and outcomes of two interventions to maximize engagement of chronically ill adolescents during hospital consultations: a mixed methods study. Journal of Pediatric Nursing: 2015, 30(5), 757-775

The need to align pediatric and adult services was evident from our findings. Transitional care should not be confined to a pediatric paradigm (Kennedy \& Sawyer, 2008). The transition process continues into young adulthood and consequently to adult care (Colver \& Longwell, 2013). In our study, nurses emphasized the importance of continued attention for competency-building after transfer and the use of ITPs for this purpose. In the Action program, nurses played a pivotal role as team leaders, designers and implementers of interventions, and as connectors of pediatric and adult services. Indeed, nurses are in a unique position to shape adolescent patients' health communication skills by involving them in decision-making, encouraging their independence and responsibility for selfmanagement, and by well preparing them for the transfer to adult care (Betz, 2006, 2013). As such, the nursing role in adolescent care deserves to be expanded.

\section{Strengths and Limitations}

Strengths of this study include the mixed methods design that aimed at gaining a more complete understanding of the quality improvement accomplishments. Multiple data sources produce more evidence, and we could link the experiences of professionals and contextual information to outcomes in patients and to process data (Cretin et al., 2004). Integration of qualitative and quantitative data remains a challenge in this type of research (Bryman, 2007), but we succeeded in achieving this due to the fact that the patient-related outcomes could be linked to the interventions' content. Since details of transition program content are rarely described and few studies so far have applied and evaluated interventions in practice (Binks, Barden, Burke, \& Young, 2007), this study contributes to more understanding of the impact of these programs on adolescents' and professionals' experiences with transitional care delivery.

Another strong feature of the study is its longitudinal design with short term and long term follow-up. We followed 22 hospital teams from all over the Netherlands, working in different settings, and included over 400 adolescents and young adults. The response rates varied across teams indicating a potential danger of non-response bias, but the rates are comparable to other studies in which the respondents received a questionnaire by mail (Picavet, 2001). However, the small number of respondents per team limited the possibilities for team-level analysis (including comparison between adopting and non-adopting teams) and long term follow-up data were available for only about half of the respondents.

In the qualitative study, we included a large number of respondents, at least two from each team, which allowed to compare and validate findings from both adopting and non-adopting teams. Although we have collected a rich description of how the interventions work in everyday practice and of professional perceptions and experiences, adolescent and parent views were not sought. While this is one of the first studies presenting data on the implementation process of transitional care interventions, conclusive information about how the interventions were executed in practice is lacking.

With respect to the outcome evaluation, the effects cannot be ascribed with certainty to the interventions because control groups were not included. In addition, comparison between teams that did or did not implement these specific interventions was not possible. Still, we would like to suggest that the improvement in outcomes provides some evidence for the effectiveness of the mix of interventions, as the outcomes were directly related to the content of the interventions (improving 
Staa, A. van, Sattoe, J.N.T., Strating, M.M.H. Experiences with and outcomes of two interventions to maximize engagement of chronically ill adolescents during hospital consultations: a mixed methods study. Journal of Pediatric Nursing: 2015, 30(5), 757-775

adolescents' independent behaviors; discussing non-medical topics during consultations). We also lack data on clinical outcomes in the teams, which could be considered a weakness. More work remains to be done to evaluate what is linked with long-term success and the effectiveness of transition programs (Bloom et al., 2012); implying that more robust designs are needed. Besides, it would be worthwhile to pay more attention to societal effects and costs (Prior, McManus, White \& Davidson, 2014).

\section{CONCLUSION}

Developmentally-appropriate interventions enhance the quality of patient-provider communication and contribute to preparing adolescents with chronic conditions for the transition to adult care. Two such interventions, seeing adolescents independently for part of the consultation and using comprehensive Individual Transition Plans, were successfully developed and implemented in the Dutch Quality Improvement collaborative 'On Your Own Feet Ahead!'. Professionals were predominantly positive about their first experiences and patient outcomes demonstrated an increase in independent behaviors, the discussion of non-medical topics and the satisfaction with care. Nurses played an important role in the development and execution of the interventions, confirming their central role in encouraging adolescent responsibility for self-management and preparing them for transition to adult life and adult care.

The following are the supplementary data related to this article.

Download Word document (20KB)Help with docx files

Supplementary file A. Scales and items used in the evaluation study On Your Own Feet Ahead!

Download Word document (43KB)Help with doc files

Supplementary file B. Domains of the Basic Individual Transition Plan ('On Your Own Feet Ahead!') and Skills for Growing Up instruments.

\section{Funding}

This research was funded with a grant from the Netherlands organization for health research and development (ZonMw) grant number: 15700.2014. Funding for the Action Program 'On Your Own Feet Ahead!' came from the Dutch Health Care Insurers' Innovation Fund with additional support from the Dutch Kidney Foundation and the National Action Program Diabetes.

\section{Author's Contribution}

AvS and MS drafted the design for data gathering and were involved in the data collection acquisition. MS and JS performed the statistical analyses, while AvS and JS conducted the analysis of the qualitative data. AvS drafted the manuscript while MS and JN contributed to refinement. All authors have read and approved its final version.

\section{Competing Interests}

The authors declare that they have no conflict of interest and confirm all patient/personal identifiers have been removed or disguised so the patient/person(s) described are not identifiable and cannot be identified through the details of the story. 
Staa, A. van, Sattoe, J.N.T., Strating, M.M.H. Experiences with and outcomes of two interventions to maximize engagement of chronically ill adolescents during hospital consultations: a mixed methods study. Journal of Pediatric Nursing: 2015, 30(5), 757-775

\section{Presentations}

Data from this manuscript have been presented at the following meetings: 18th Congress International Association Adolescent Health - Paris (2014); 2nd Pediatric Psychology Conference - Amsterdam (2014); 18th EACH International Conference on Communication in Healthcare - Amsterdam (2014).

\section{Acknowledgements}

We thank all participating teams of professionals for their enthusiastic contribution to the Action Program 'On Your Own Feet Ahead!'. Also, the support of our colleagues Jeroen Havers MSc and Ingrid Janssen MSc (CBO), Lausanne Mies MSc and Susan Jedeloo $\mathrm{PhD}$ (Rotterdam University of Applied Sciences) in supervising the program and supporting all its' activities is gratefully acknowledged. Furthermore, we thank Anna Nieboer PhD, Marij Roebroeck PhD and Henk Sonneveld MSc for their participation in the research group and their contribution to the design of the evaluation study and the development of the instruments used. Furthermore, we recognize Ko Hagoort's contribution to the editing of the manuscript.

Erasmus University Bachelor and Master students in the Health Sciences contributed to the interviews with professionals: Latifa Adjij, Gisele Frank, Ilse Gianotten, Linda Hoekman, Hanneke Meeuwsen, Else ter Meulen, Priti Sethi, Ofra Simon, Inge den Uijl, and Sanne Wesseling. Bachelor of Nursing students from Rotterdam University of Applied Sciences (Andrea Blok, Daniella Kramp, Lisette van Sinttruije, and Evelien Polderman) helped to collect qualitative data in the nephrology teams.

\section{REFERENCES}

A.E. Ambresin, K. Bennett, G.C. Patton, L.A. Sanci, S.M. Sawyer Assessment of youthfriendly health care: a systematic review of indicators drawn from young people's perspectives Journal of Adolescent Health, 52 (2013), pp. 670-681, 10.1016/j.jadohealth.2012.12.014

American Academy of Pediatrics, American Academy of Family Physicians, American College of Physicians, Transitions Clinical Report Authoring Group, W.C. Cooley, P.J. Sagerman Supporting the health care transition from adolescence to adulthood in the medical home Pediatrics, 128 (2011), pp. 182-200, 10.1542/peds.2011-0969

R.A. Annunziato, D. Freiberger, K. Martin, J. Helcer, C. Fitzgerald, D.S. Lefkowitz An empirically based practice perspective on the transition to adulthood for solid organ transplant recipients Pediatric Transplantation, 18 (2014), pp. 794-802, 10.1111/petr.12359

J.J. Arnett Emerging adulthood. A theory of development from the late teens through the twenties The American Psychologist, 55 (2000), pp. 469-480

E.D. Berlan, T. Bravender Confidentiality, consent, and caring for the adolescent patient Current Opinion in Pediatrics, 21 (2009), pp. 450-456, 10.1097/MOP.0b013e32832ce009

C.L. Betz Self-management and adherence of children and youth with special health care needs: implications for pediatric nursing practice Journal of Pediatric Nursing, 21 (2006), pp. 253-255, 10.1016/j.pedn.2006.04.003

C.L. Betz Health care transition for adolescents with special healthcare needs: where is nursing? Nursing Outlook, 61 (2013), pp. 258-265, 10.1016/j.outlook.2012.08.009

C.L. Betz, M.L. Lobo, W.M. Nehring, K. Bui Voices not heard: a systematic review of adolescents' and emerging adults' perspectives of health care transition Nursing Outlook, 61 (2013), pp. 311-336, 10.1016/j.outlook.2013.01.008

J.A. Binks, W.S. Barden, T.A. Burke, N.L. Young What do we really know about the transition to adult-centered health care? A focus on cerebral palsy and spina bifida. Archives of Physical Medicine and Rehabilitation, 88 (2007), pp. 1064-1073, 10.1016/j.apmr.2007.04.018 
Staa, A. van, Sattoe, J.N.T., Strating, M.M.H. Experiences with and outcomes of two interventions to maximize engagement of chronically ill adolescents during hospital consultations: a mixed methods study. Journal of Pediatric Nursing: 2015, 30(5), 757-775

S.R. Bloom, K. Kuhlthau, J. Van Cleave, A.A. Knapp, P. Newacheck, J.M. Perrin Health care transition for youth with special health care needs Journal of Adolescent Health, 51 (2012), pp. 213-219, 10.1016/j.jadohealth.2012.01.007

M.T. Britto, R.F. DeVellis, R.W. Hornung, G.H. DeFriese, H.D. Atherton, G.B. Slap Health care preferences and priorities of adolescents with chronic illnesses Pediatrics, 114 (2004), pp. $1272-1280$

A. Bryman Barriers to Integrating Quantitative and Qualitative Research Journal of Mixed Methods Research, 1 (2007), pp. 8-22, 10.1177/2345678906290531

J. Carlisle, D. Shickle, M. Cork, A. McDonagh Concerns over confidentiality may deter adolescents from consulting their doctors. A qualitative exploration Journal of Medical Ethics, 32 (2006), pp. 133-137

A. Colver, S. Longwell New understanding of adolescent brain development: relevance to transitional healthcare for young people with long term conditions Archives of Diseases in Childhood, 98 (2013), pp. 902-907, 10.1136/archdischild-2013-303945

Committee on Adolescence American Academy of Pediatrics Achieving quality health services for adolescents Pediatrics, 121 (2008), pp. 1263-1270, 10.1542/peds.2008-0694

I. Coyne Children's participation in consultations and decision-making at health service level: a review of the literature International Journal of Nursing Studies, 45 (2008), pp. 16821689, 10.1016/j.jijnurstu.2008.05.002

S. Cretin, S.M. Shortell, E.B. Keeler An evaluation of collaborative interventions to improve chronic illness care. Framework and study design Evaluation Review, 28 (2004), pp. 28-51, $10.1177 / 0193841 \times 03256298$

M.R. Dimatteo The role of effective communication with children and their families in fostering adherence to pediatric regimens Patient Education and Counseling, 55 (2004), pp. 339-344

G. Dovey-Pearce, R. Hurrell, C. May, C. Walker, Y. Doherty Young adults' (16-25 years) suggestions for providing developmentally appropriate diabetes services: a qualitative study Health \& Social Care in the Community, 13 (2005), pp. 409-419

J. Downing, H.K. Gleeson, P.E. Clayton, J.R. Davis, J.K. Wales, P. Callery Transition in endocrinology: the challenge of maintaining continuity Clinical Endocrinology (Oxford), 78 (2013), pp. 29-35, 10.1111/j.1365-2265.2012.04473.x

R.E. Duncan, M. Jekel, M.A. O'Connell, L.A. Sanci, S.M. Sawyer Balancing parental involvement with adolescent friendly health care in teenagers with diabetes: are we getting it right? Journal of Adolescent Health, 55 (2014), pp. 59-64, 10.1016/j.jadohealth.2013.11.024

S. Elo, H. Kyngäs The qualitative content analysis process Journal of Advanced Nursing, 62 (2008), pp. 107-115, 10.1111/j.1365-2648.2007.04569.x

A. English, C.A. Ford More evidence supports the need to protect confidentiality in adolescent health care Journal of Adolescent Health, 40 (2007), pp. 199-200, 10.1016/j.jadohealth.2006.12.016

L. Fegran, E.O. Hall, L. Uhrenfeldt, H. Aagaard, M.S. Ludvigsen Adolescents' and young adults' transition experiences when transferring from paediatric to adult care: A qualitative metasynthesis International Journal of Nursing Studies, 51 (2014), pp. 123-135, 10.1016/j.ijnurstu.2013.02.001

M.E. Ferris, J.R. Cuttance, K. Javalkar, S.E. Cohen, A. Phillips, K. Bickford, et al.Selfmanagement and transition among adolescents/young adults with chronic or end-stage kidney disease Blood Purification, 39 (2015), pp. 99-104, 10.1159/000368978

C.A. Ford, A.F. Davenport, A. Meier, A.L. McRee Partnerships between parents and health care professionals to improve adolescent health Journal of Adolescent Health, 49 (2011), pp. 53-57, 10.1016/j.jadohealth.2010.10.004

C. Ford, A. English, G. Sigman Confidential Health Care for Adolescents: Position Paper for the Society for Adolescent Medicine Journal of Adolescent Health, 35 (2004), pp. 160-167

C.A. Ford, S.G. Millstein, B.L. Halpern-Felsher, C.E. Irwin Jr. Influence of physician confidentiality assurances on adolescents' willingness to disclose information and seek future health care. A randomized controlled trial JAMA, 278 (1997), pp. 1029-1034

K.C. Garvey, H.A. Wolpert, L.M. Laffel, E.T. Rhodes, J.I. Wolfsdorf, J.A. Finkelstein Health care transition in young adults with type 1 diabetes: barriers to timely establishment of adult diabetes care Endocrine Practice, 19 (2013), pp. 946-952, 10.4158/EP13109.OR 
Staa, A. van, Sattoe, J.N.T., Strating, M.M.H. Experiences with and outcomes of two interventions to maximize engagement of chronically ill adolescents during hospital consultations: a mixed methods study. Journal of Pediatric Nursing: 2015, 30(5), 757-775

A.L. Gilbert, V.I. Rickert, M.C. Aalsma Clinical conversations about health: the impact of confidentiality in preventive adolescent care Journal of Adolescent Health, 55 (2014), pp. 672-677, 10.1016/j.jadohealth.2014.05.016

A.M. Gravelle, M. Paone, A.G. Davidson, M.A. Chilvers Evaluation of a multidimensional cystic fibrosis transition program: a quality improvement initiative Journal of Pediatric Nursing, 30 (2015), pp. 236-243, 10.1016/j.pedn.2014.06.011

L. Haverman, M.A. van Rossum, M. van Veenendaal, J.M. van den Berg, K.M. Dolman, J. Swart, et al.Effectiveness of a web-based application to monitor health-related quality of life Pediatrics, 131 (2013), pp. e533-e543, 10.1542/peds.2012-0958

Institute for Healthcare Improvement $(\mathrm{IHI})$ The Breakthrough Series: IHI's collaborative model for achieving breakthrough improvement IHI Innovation Series white paper, Institute for Healthcare Improvement, Boston (2003)

A. Kennedy, S. Sawyer Transition from pediatric to adult services: are we getting it right? Current Opinion in Pediatrics, 20 (2008), pp. 403-409, 10.1097/MOP.0b013e328305e128

G.M. Kieckhefer, C.M. Trahms Supporting development of children with chronic conditions: from compliance toward shared management Pediatric Nursing, 26 (2000), pp. 354-363

B.K. Klostermann, G.B. Slap, D.M. Nebrig, T.L. Tivorsak, M.T. Britto Earning trust and losing it: adolescents' views on trusting physicians Journal of Family Practice, 54 (2005), pp. 679687

W. Martinez, J.S. Carter, L.J. Legato Social competence in children with chronic illness: a meta-analytic review Journal of Pediatric Psychology, 36 (2011), pp. 878-890, 10.1093/jpepsy/jsr035

M. McManus, P. White, A. Barbour, B. Downing, K. Hawkins, N. Quion, et al.Pediatric to adult transition: a quality improvement model for primary care Journal of Adolescent Health, 56 (2015), pp. 73-78, 10.1016/j.jadohealth.2014.08.006

A.C. Modi, A.L. Pai, K.A. Hommel, K.K. Hood, S. Cortina, M.E. Hilliard, et al.Pediatric selfmanagement: a framework for research, practice, and policy Pediatrics, 129 (2012), pp. e473-e485, 10.1542/peds.2011-1635

M. Monaghan, M. Hilliard, R. Sweenie, K. Riekert Transition readiness in adolescents and emerging adults with diabetes: the role of patient-provider communication Current Diabetes Reports, 13 (2013), pp. 900-908, 10.1007/s11892-013-0420-x

M. Moynihan, E. Saewyc, S. Whitehouse, M. Paone, G. McPherson Assessing readiness for transition from paediatric to adult health care: Revision and psychometric evaluation of the Am I ON TRAC for Adult Care questionnaire Journal of Advanced Nursing, 71 (2015), pp. 1324-1335, 10.1111/jan.12617

A.P. Nieboer, J.M. Cramm, H.M. Sonneveld, M.E. Roebroeck, A. van Staa, M.M. Strating Reducing bottlenecks: professionals' and adolescents' experiences with transitional care delivery BMC Health Services Research, 14 (2014), p. 47, 10.1186/1472-6963-14-47

M.C. Paone, M. Wigle, E. Saewyc The ON TRAC model for transitional care of adolescents Progress in Transplantation, 16 (2006), pp. 291-302

H.S. Picavet National health surveys by mail or home interview: effects on response Journal of Epidemiology and Community Health, 55 (2001), pp. 408-413

M. Prior, M. McManus, P. White, L. Davidson Measuring the "triple aim" in transition care: a systematic review Pediatrics, 134 (2014), pp. e1648-e1661, 10.1542/peds.2014-1704

E. Pyörälä The participation roles of children and adolescents in the dietary counseling of diabetics Patient Education and Counseling, 55 (2004), pp. 385-395

J. Reiss, R. Gibson Health care transition: destinations unknown Pediatrics, 110 (2002), pp. 1307-1314

L.P. Robertson, J.E. McDonagh, T.R. Southwood, K.L. Shaw Growing up and moving on. A multicentre UK audit of the transfer of adolescents with juvenile idiopathic arthritis from paediatric to adult centred care Annals of the Rheumatic Diseases, 65 (2006), pp. 74-80

C. Rutishauser, A. Esslinger, L. Bond, F.H. Sennhauser Consultations with adolescents: the gap between their expectations and their experiences Acta Paediatrica, 92 (2003), pp. $1322-1326$

R.A. Sasse, R.A. Aroni, S.M. Sawyer, R.E. Duncan Confidential consultations with adolescents: an exploration of Australian parents' perspectives Journal of Adolescent Health, 52 (2013), pp. 786-791, 10.1016/j.jadohealth.2012.11.019 
Staa, A. van, Sattoe, J.N.T., Strating, M.M.H. Experiences with and outcomes of two interventions to maximize engagement of chronically ill adolescents during hospital consultations: a mixed methods study. Journal of Pediatric Nursing: 2015, 30(5), 757-775

J.N. Sattoe, S.R. Hilberink, M.A. Peeters, A. van Staa 'Skills for Growing up': Supporting Autonomy in Young People with Kidney Disease Journal of Renal Care, 40 (2014), pp. 131-139, 10.1002/jorc.12046

G.S. Sawicki, S. Kelemen, E.R. Weitzman Ready, set, stop: mismatch between self-care beliefs, transition readiness skills, and transition planning among adolescents, young adults, and parents Clinical Pediatrics (Philadelphia), 53 (2014), pp. 1062-1068, $10.1177 / 0009922814541169$

G.S. Sawicki, K. Lukens-Bull, X. Yin, N. Demars, I.C. Huang, W. Livingood, et al.Measuring the transition readiness of Youth with Special Healthcare Needs: validation of the TRAQ-Transition Readiness Assessment Questionnaire Journal of Pediatric Psychology, 36 (2011), pp. 160-171, 10.1093/jpepsy/jsp128

S.M. Sawyer Action plans, self-monitoring and adherence: changing behaviour to promote better self-management The Medical Journal of Australia, 177 (2002), pp. S72-S74

(Supplement)

S.M. Sawyer, S. Drew, M.S. Yeo, M.T. Britto Adolescents with a chronic condition: challenges living, challenges treating Lancet, 369 (2007), pp. 1481-1489, 10.1016/S01406736(07)60370-5

R. Schwarzer, M. Jerusalem Generalized Self-Efficacy scale

J. Weinmann, S. Wright, M. Johnston (Eds.), Measures in health psychology: A user's portfolio. Causal and control beliefs, Windsor, NFER-NELSON (1995), pp. 35-37

K.L. Shaw, T.R. Southwood, J.E. McDonagh Development and preliminary validation of the 'Mind the Gap' scale to assess satisfaction with transitional health care among adolescents with juvenile idiopathic arthritis

Child: Care, Health and Development, 33 (2007), pp. 380-388

K.L. Shaw, T.R. Southwood, J.E. McDonagh Young people's satisfaction of transitional care in adolescent rheumatology in the UK Child: Care, Health and Development, 33 (2007), pp. 368-379

H.M. Sonneveld, M.M. Strating, A.L. van Staa, A.P. Nieboer Gaps in transitional care: what are the perceptions of adolescents, parents and providers? Child: Care, Health and Development, 39 (2013), pp. 69-80, 10.1111/j.1365-2214.2011.01354.x

J.C. Surís, C. Akre, C. Rutishauser How adult specialists deal with the principles of a successful transition Journal of Adolescent Health, 45 (2009), pp. 551-555, 10.1016/j.jadohealth.2009.05.011

J.C. Surís, C. Rutishauser, C. Akre Est-ce qu'en discuter fait la difference? Opinions de jeunes adultes atteints de maladies chroniques apres avoir ete transferes vers des soins pour adultes. [Does talking about it make a difference? Opinions of chronically ill young adults after being transferred to adult care] Archives of Pediatrics, 22 (2015), pp. 267-271, 10.1016/j.arcped.2014.12.001

A.L. van Staa On Your Own Feet: Preferences and Competencies for Care of Adolescents with Chronic Conditions (PhD Thesis)

Erasmus University Rotterdam, Rotterdam (2012)

(Retrieved from http://repub.eur.nl/res/pub/32973/)

A.L. van Staa, S. Jedeloo, H.A. van der Stege, On Your Own Feet Research Group "What we want": chronically ill adolescents' preferences and priorities for improving health care Patient Preference and Adherence, 5 (2011), pp. 291-305, 10.2147/PPAS17184

A.L. van Staa, S. Jedeloo, J. van Meeteren, J.M. Latour Crossing the transition chasm: experiences and recommendations for improving transitional care of young adults, parents and providers Child: Care, Health and Development, 37 (2011), pp. 821-832, 10.1111/j.1365-2214.2011.01261.x

A. van Staa, On Your Own Feet Research Group Unraveling triadic communication in hospital consultations with adolescents with chronic conditions: The added value of mixed methods research Patient Education and Counseling, 82 (2011), pp. 455-464, 10.1016/j.pec.2010.12.001

A.L. van Staa, J.N.T. Sattoe Young adults' experiences and satisfaction with the transfer of care Journal of Adolescent Health, 55 (2014), pp. 796-803, 10.1016/j.jadohealth.2014.06.008

A.L. van Staa, Eysink Smeets-van, A.E. de Burgt, H.A. van der Stege, S.R. Hilberink Transitie in zorg van jongeren met chronische aandoeningen in Nederland nog onder de 
Staa, A. van, Sattoe, J.N.T., Strating, M.M.H. Experiences with and outcomes of two interventions to maximize engagement of chronically ill adolescents during hospital consultations: a mixed methods study. Journal of Pediatric Nursing: 2015, 30(5), 757-775

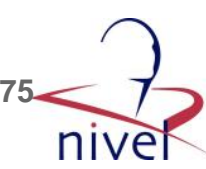

maat [Transition in care for young people with chronic conditions: substandard in the

Netherlands] Tijdschrift voor Kindergeneeskunde, 78 (2010), pp. 227-236

A.L. van Staa, H.A. van der Stege, S. Jedeloo, H.A. Moll, S.R. Hilberink Readiness to transfer to adult care of adolescents with chronic conditions: exploration of associated factors Journal of Adolescent Health, 48 (2011), pp. 295-302,

10.1016/j.jadohealth.2010.07.009

R.M. Viner Transition of care from paediatric to adult services: one part of improved health services for adolescents Archives of Diseases in Childhood, 93 (2008), pp. 160-163, 10.1136/adc.2006.103721

G. Wang, B.B. McGrath, C. Watts Health care transitions among youth with disabilities or Special Health Care Needs: an ecological approach Journal of Pediatric Nursing, 25 (2009), pp. 505-550

WGBO (Dutch Medical Treatment Act) Part of the Dutch Burgerlijk Wetboek (=civil code)

Retrieved at: http://wetten.overheid.nl/BWBR0005290/volledig/geldigheidsdatum_20-092012\#Boek7_Titel7_Afdeling5 (1995)

E. Wassmer, G. Minnaar, N. Abdel Aal, M. Atkinson, E. Gupta, S. Yuen, et al.How do paediatricians communicate with children and parents? Acta Paediatrica, 93 (2004), pp. 1501-1506, 10.1080/08035250410015079

D.L. Wood, G.S. Sawicki, M.D. Miller, C. Smotherman, K. Lukens-Bull, W.C. Livingood, et al.The Transition Readiness Assessment Questionnaire (TRAQ): its factor structure, reliability, and validity Academic Pediatrics, 14 (2014), pp. 415-422,

10.1016/j.acap.2014.03.008

L.F. Zhang, J.S. Ho, S.E. Kennedy A systematic review of the psychometric properties of transition readiness assessment tools in adolescents with chronic disease BMC Pediatrics, 14 (2014), p. 4, 10.1186/1471-2431-14-4

K.B. Zolnierek, M.R. DimatteoPhysician communication and patient adherence to treatment: a meta-analysis Medical Care, 47 (2009), pp. 826-834, 10.1097/MLR.0b013e31819a5ac

\section{TABLES AND FIGURES}

Table 1. Overview of most often applied interventions in the Action Program 'On Your Own Feet Ahead!' in all hospital teams $(n=22)$ a

\begin{tabular}{|c|c|c|c|c|c|c|}
\hline Interventions implemented & $\begin{array}{c}\text { DM1 } \\
(11 \\
) \mathrm{b}\end{array}$ & $\begin{array}{r}\mathrm{CKD} \\
(4)\end{array}$ & \begin{tabular}{|c} 
JIA \\
( \\
2 \\
) \\
\end{tabular} & & $\begin{array}{l}\text { Others } \\
\text { (3) }\end{array}$ & Total number of teams (\%) \\
\hline \multicolumn{7}{|l|}{ Interventions to improve organization of transition } \\
\hline $\begin{array}{l}\text { Regular consultations between pediatric and adult } \\
\text { care (incl. multidisciplinary transfer meetings) }\end{array}$ & 11 & 4 & 2 & 2 & 2 & $21(95.5 \%)$ \\
\hline Transition clinic/youth clinic & 10 & 2 & 2 & 2 & 2 & $18(81.8 \%)$ \\
\hline Transition protocol & 4 & 4 & 2 & 1 & 3 & $14(63.6 \%)$ \\
\hline Transition coordinator & 5 & 2 & 1 & 1 & 1 & $10(45.5 \%)$ \\
\hline $\begin{array}{l}\text { Joint policy \& mission between pediatric and adult } \\
\text { care }\end{array}$ & 2 & 1 & 2 & 2 & 2 & $9(40.9 \%)$ \\
\hline \multicolumn{7}{|c|}{ Interventions to enhance self-management and transition readiness } \\
\hline Checklist for transition (professional use) & 11 & 1 & 2 & 2 & 3 & $19(86.4 \%)$ \\
\hline $\begin{array}{l}\text { Individual Transition Plans (adolescent and parent } \\
\text { use)c }\end{array}$ & 8 & 4 & 2 & 1 & 1 & $16(72.7 \%)$ \\
\hline Independent consultationsd & 9 & 2 & 1 & 1 & 1 & $14(63.6 \%)$ \\
\hline Information leaflet/website for youth & 5 & 3 & 1 & 1 & 2 & $12(54.4 \%)$ \\
\hline $\begin{array}{l}\text { Patient Reported Outcomes (Quality of Life } \\
\text { questionnaires) }\end{array}$ & 7 & 2 & 1 & 2 & 0 & $12(54.5 \%)$ \\
\hline
\end{tabular}

${ }^{\text {a }}$ Measured two years after start (T2). 
Staa, A. van, Sattoe, J.N.T., Strating, M.M.H. Experiences with and outcomes of two interventions to maximize engagement of chronically ill adolescents during hospital consultations: a mixed methods study. Journal of Pediatric Nursing: 2015, 30(5), 757-775

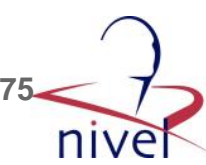

${ }^{b} \mathrm{DM} 1=$ diabetes mellitus type $1 ; \mathrm{CKD}=$ chronic kidney disease \& transplantation; $\mathrm{JIA}=$ juvenile idiopathic arthritis; $\mathrm{CF}=$ cystic fibrosis; others $=$ neuromuscular disorders $(n=1)$; congenital urology $(n=1)$; hiv $(n=1)$.

'All nephrology teams used the new instrument 'Skills for Growing Up-Nephrology' (Sattoe et al., 2014).

dOnly teams that implemented Independent Consultations as standard policy are listed.

Figure 1. Process and effect evaluation of the Action Program 'On Your Own Feet Ahead!'. Process evaluation

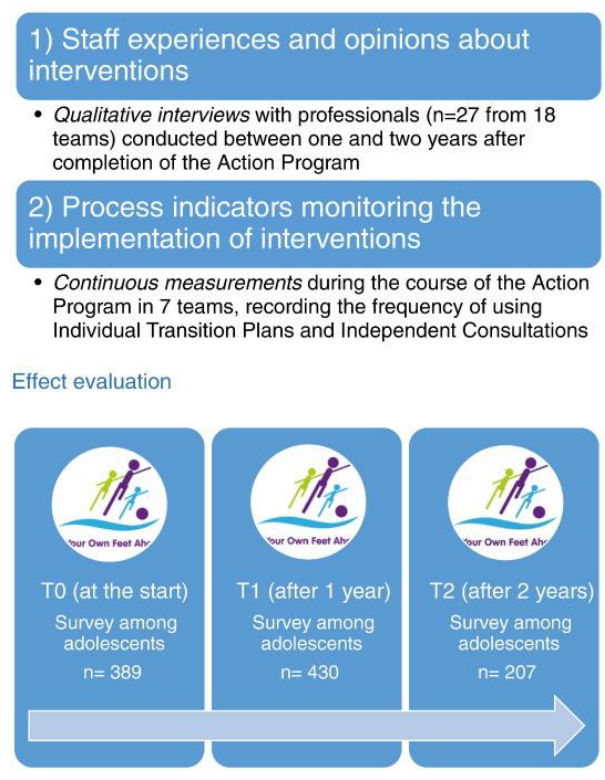

Table 2. Characteristics of interviewees ( $n=37$ from 18 teams participating in the Action Program 'On Your Own Feet Ahead!')a

\begin{tabular}{|l|l|l|}
\hline Professional background $(\mathrm{n}=37)$ & $\mathrm{n}(\%)$ & Project leader \\
\hline Nurse specialist (PC) & $17(46.0)$ & $\mathrm{n}=10$ \\
\hline Nurse specialist (AC) & $6(16.2)$ & $\mathrm{n}=1$ \\
\hline Nurse specialist working in both settings & $1(2.7)$ & $\mathrm{n}=1$ \\
\hline Pediatrician (PC) & $9(24.3)$ & $\mathrm{n}=2$ \\
\hline Medical specialist (AC) & $1(2.7)$ & $\mathrm{n}=1$ \\
\hline Social worker (PC) & $2(5.4)$ & \\
\hline Manager (PC) & $1(2.7)$ & \\
\hline Care setting ( $\mathrm{n}=37)$ & $\mathrm{n}(\%)$ & \\
\hline Pediatric care (PC) & $29(78.4)$ & \\
\hline Adult care (AC) & $7(18.9)$ & \\
\hline Both & $1(2.7)$ & \\
\hline Specialty teams $(\mathrm{n}=18)$ & $\mathrm{n}(\%)$ & \\
\hline Diabetes mellitus type 1 & $9(50.0 \%)$ & \\
\hline Cystic fibrosis & $2(11.1 \%)$ & \\
\hline Juvenile idiopathic arthritis & $2(11.1 \%)$ & \\
\hline Chronic kidney disease & $4(22.2 \%)$ & \\
\hline Neuromuscular disorders & $1(5.6 \%)$ & \\
\hline
\end{tabular}

A Four teams did not participate in the interview study. 
Staa, A. van, Sattoe, J.N.T., Strating, M.M.H. Experiences with and outcomes of two interventions to maximize engagement of chronically ill adolescents during hospital consultations: a mixed methods study. Journal of Pediatric Nursing: 2015, 30(5), 757-775

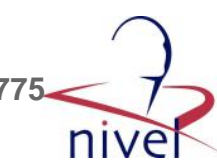

Table 3. Key reasons and advantages proposed for adopting or not adopting Independent Consultations

Reasons for adopting the intervention

Building adolescents' transition capacity and readiness:

In adult care, parents are welcome only during the first consultation, after that the young person is expected to manage his own affairs. Therefore, it is a good thing that adolescents are getting used to doing some of the consultation on their own starting from the age of twelve. Nurse PC-DM1\#24
Reasons for not adopting the intervention

- Fear of excluding parents; importance of parent role in adolescent care

It's very hard for parents to leave their child on their own and they have an urge to hold on. In adult care we should be sensitive to this and make sure that we involve parents in the communication. Nurse AC-CF-\#6

- No need to implement a standard policy, only in case of parental dominance

When it really turns difficult and a parent is very dominant and this bothers us, then we ask to see the patient alone. But this can become very nasty and painful. Then parents often feel excluded. Nurse AC-CF-\#6

- Preference to let adolescents and parents decide; not wishing to impose the intervention:

I try to work towards independence, in a playful way; not pushing it. ... As long as the child is an active partner in the communication then it's fine with me. I have no objection to parents being present then. When you're chronically ill, you like to be supported. Nurse PC-CF-\#6

The child and parents are in this together and we are not really the ones to change the system. We can explain the advantages, but ultimately it is up to them to decide - together. Doctor PCDM1-\#20

\section{Advantages of the intervention} Disadvantages of the intervention

- Independent consultations (split visits) are liked by young people and do not exclude parents:

Young people appreciate being taken seriously, parents understand that it's necessary to let go because this is a very safe intervention: in the end they are always invited in and parents are always welcome to ask questions. Nurse PC-AC-CKD-\#19 - Enhances independent behaviors during consultations:

It works very well. Some kids really seem to flourish; they talk more freely and seem more involved. Nurse PC-DM1-\#21

- Empowers young people:

The advantage of making ICs a standard policy is that young people do not need to choose to send their parents away. Nurse PC-DM1-\#12 - Enables confidential conversations about risk behaviors, sensitive issues, or adherence:

Seeing adolescents alone facilitates openness: they will be more open to discuss alcohol and drugs; and they will admit more easily to being non-adherent without parents present. Doctor PCDM1-\#28

- Simple intervention with direct effect:

It is a simple and non-time-consuming intervention and very successful. At a certain point in time, when they're about 16, 17 years old, they all come by themselves - we didn't see that before. Nurse PC-DM1-\#21
- No disadvantages as long as the intervention is applied in a flexible manner and parents are not excluded: you wish to pursue. In the end it's the patient who decides. (...) So you should not be too strict. But you have to keep in mind that the adolescent must learn to do it independently. So you have to suggest: maybe it's a good idea to come on your own next time, or even: next time I want to see you alone. Because it is all about YOU. Now you're mum does the talking, but I want YOUR answers. Nurse PC-DM1-\#29

- Team consensus is needed:

Not all team members were convinced of the need for the intervention. Nurse PC-NMD-\#4

- Parents may resist the intervention

I foresee a lot of resistance from parents and endless debates in our team. Doctor PC-JIA-\#17
If she wants to bring her mum, you have to ask yourself whether 
Staa, A. van, Sattoe, J.N.T., Strating, M.M.H. Experiences with and outcomes of two interventions to maximize engagement of chronically ill adolescents during hospital consultations: a mixed methods study. Journal of Pediatric Nursing: 2015, 30(5), 757-775

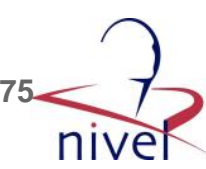

Table 4. Key reasons and advantages proposed for adopting or not adopting Individual

Transition Plans

Reasons for adopting the intervention Reasons for not adopting the intervention

- Identification of gaps in knowledge and skills in the development of autonomy and designating specific goals for patient education:

It gives us guidance to support young people and their parents. It concretizes what transition really implies.

Nurse PC-CKD-\#30

The ITP shows you what issues you still need to address in your education, for example fertility, sexuality, and knowledge about medications. Nurse AC-CF-\#11

- As a communicational tool, ITPs encourage patientcentered communication and empower adolescents: The ITP serves as a point of departure for the discussion, but it should be applied in a flexible way (...) the principle really is that we assess what adolescents wish or require to learn, and to understand what they need. Nurse PC-JIA-\#3

Advantages of the intervention

- Lack of time and staff may impede the implementation of ITPs

- Preference for using a checklist for professionals instead

For me, it suffices to work with a simple checklist that I keep in my files. This helps me to address all transition-related items. Nurse PC-DM\#5

- Raising awareness about the importance of adolescents becoming independent and the need for holistic transitional care:

The ITP has made clearer what transition really is all about. At first, I thought transition merely meant the transfer to AC. Now I learnt it's about everything involved in living with arthritis: physical activity, school, medication, alcohol, sexuality. These topics were not really addressed earlier, but they are all part of transition. Doctor PC-JIA-\#17

- Use of the ITP stimulates family interaction:

You can see the discrepancies between parent and child. Children say 'yeah I know all about it' whereas the parents deny this! That's great, because then you have something to talk about. Nurse AC\&PC-CKD-\#19

Disadvantages of the intervention

- Working with ITPs is time-consuming because they are lengthy and logistically complex:

You have to send the ITP to the patient beforehand, or present it while he or she is in the waiting room. It's a lot of hassle and we haven't solved this issue yet. Nurse PC-DM121

- Complexity increases when working with developmentally appropriate versions:

The different versions of the SGU-N are really confusing and time-consuming. Nurse PC-CKD-30

- ITPs contain self-reported data and cannot replace more objective assessments of knowledge and skills:

Adolescents will never admit to not knowing something; you still need to explore their actual competencies. I would welcome a more objective measurement. Nurse PC-CF-11

Figure 2. Process data about the implementation of independent consultations from 7 teams during their participation in the Action Program.

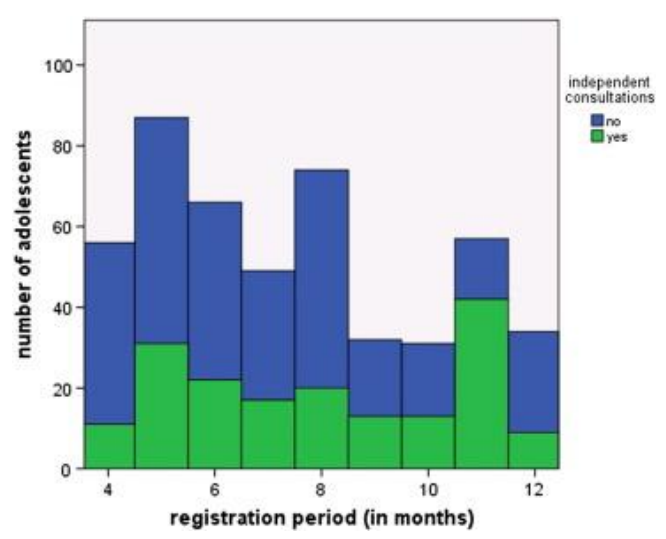

Figure 3. Process data about the implementation of individual transition plans from 7 teams during their participation in the Action Program. 
Staa, A. van, Sattoe, J.N.T., Strating, M.M.H. Experiences with and outcomes of two interventions to maximize engagement of chronically ill adolescents during hospital consultations: a mixed methods study. Journal of Pediatric Nursing: 2015, 30(5), 757-775
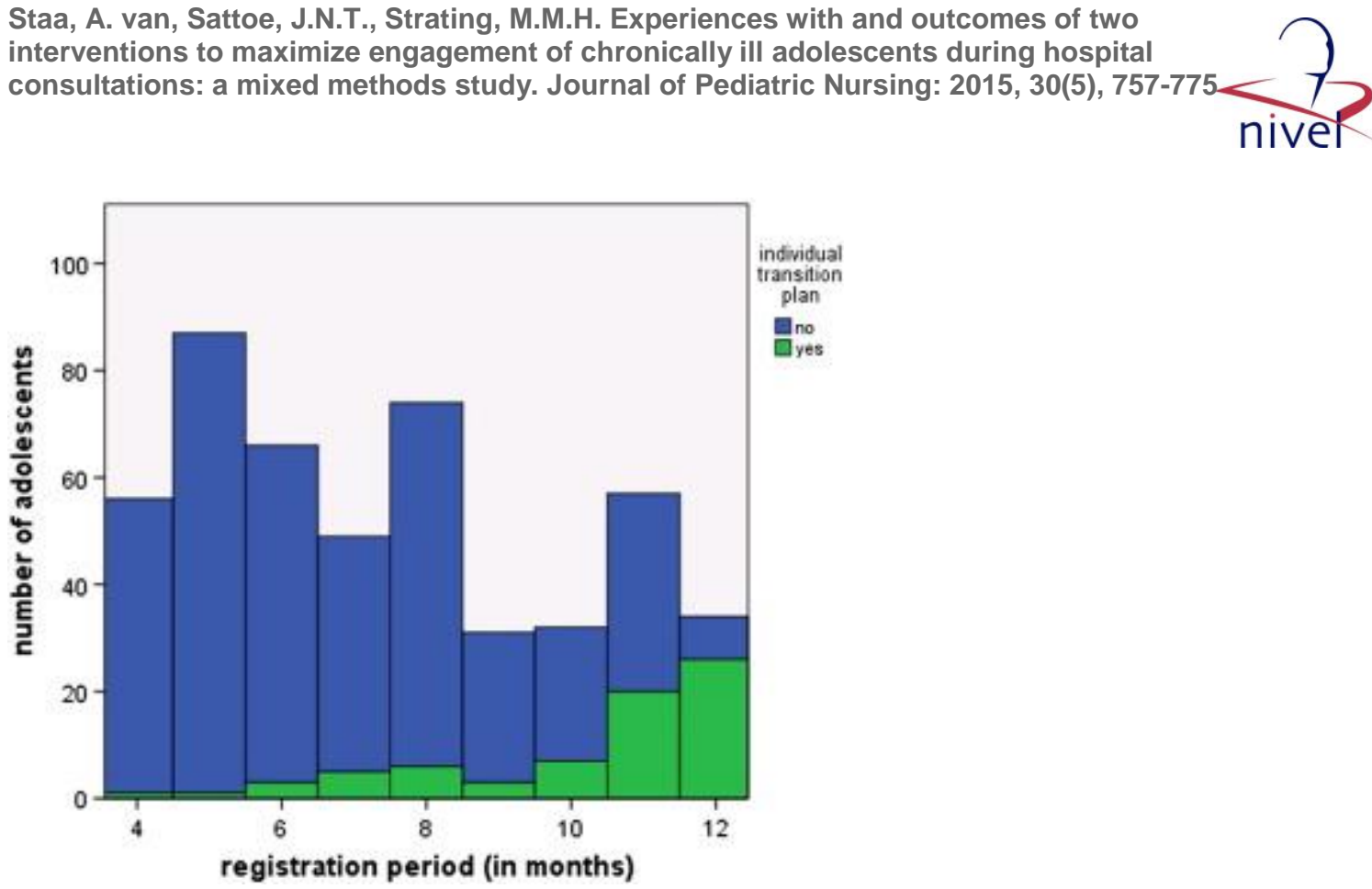

Figure 4. Overview of the response per measurement and the matches between T0-T1 and T1T2 in the evaluation study.

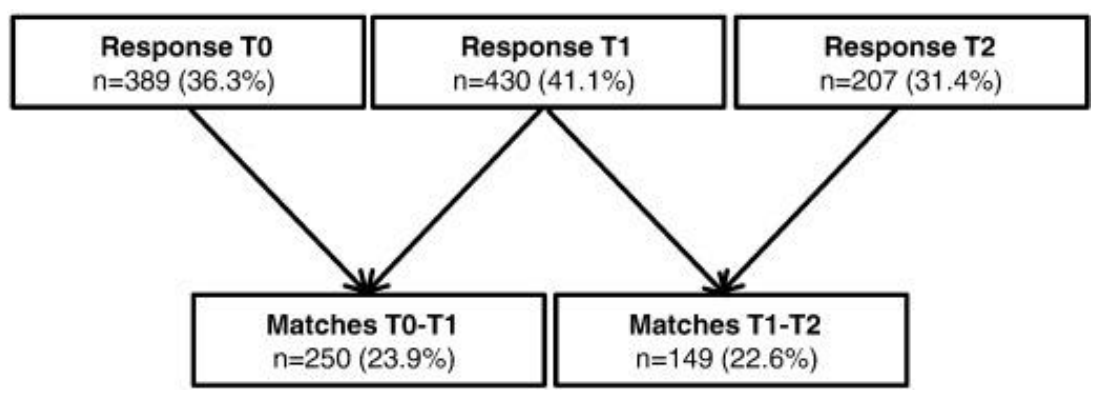

Table 5. Characteristics of adolescents and young adults in the effect evaluation of the Action Program 'On Your Own Feet Ahead!' (20 teams at T0/T1; 11 teams at T2)a

\begin{tabular}{|c|c|c|c|}
\hline & $\begin{array}{l}\mathrm{T0} \\
\mathrm{n}=389\end{array}$ & $\begin{array}{l}T 1 \\
n=430\end{array}$ & $\begin{array}{l}\mathrm{T} 2 \\
\mathrm{n}=207\end{array}$ \\
\hline \multicolumn{4}{|l|}{ Respondents' characteristics } \\
\hline Age (mean; SD) & $\begin{array}{c}16.1 \\
(2.3)\end{array}$ & $17.3(2.3)$ & $18.6(2.4)$ \\
\hline Age range [min-max] & $11-25$ & $12-26$ & 13-27 \\
\hline Gender (male) (n; \%) & \begin{tabular}{|c|}
82 \\
$(47.3)$
\end{tabular} & $183(43.9)$ & $85(42.9)$ \\
\hline Physical limitations (no) (n; \%) & \begin{tabular}{|c|}
345 \\
$(88.7)$
\end{tabular} & 371 (86.5) & $172(83.9)$ \\
\hline Diagnosis after age of $6(n ; \%)$ & \begin{tabular}{|l}
242 \\
$(62.4)$
\end{tabular} & $268(62.8)$ & $128(61.8)$ \\
\hline General health [range 1-5] (mean; SD) & $3.2(1.1)$ & $3.1(1.1)$ & $3.1(0.9)$ \\
\hline Transferred to adult care $(\mathrm{n} ; \%)$ & - & $109(25.3)$ & $96(46.6)$ \\
\hline \multicolumn{4}{|l|}{ Chronic conditions ( $\mathrm{n} ; \%)$} \\
\hline Diabetes mellitus type 1 & $\begin{array}{l}253 \\
(65.2)\end{array}$ & $268(62.9)$ & $106(51.5)$ \\
\hline Juvenile Idiopathic Arthritis & $54(13.9)$ & $82(19.2)$ & $41(19.9)$ \\
\hline Chronic Kidney Diseases & $31(8.0)$ & $21(4.9)$ & $9(4.4)$ \\
\hline
\end{tabular}


Staa, A. van, Sattoe, J.N.T., Strating, M.M.H. Experiences with and outcomes of two interventions to maximize engagement of chronically ill adolescents during hospital consultations: a mixed methods study. Journal of Pediatric Nursing: 2015, 30(5), 757-775

\begin{tabular}{|c|c|c|c|}
\hline & $\begin{array}{r}\text { T0 } \\
\mathrm{n}=389\end{array}$ & $\mathrm{~T} 1$ & $\begin{array}{r}\mathrm{T} 2 \\
\mathrm{n}\end{array}=207$ \\
\hline Neuromuscular \& neurological disorders (incl. Spina Bifida) & $35(9.0)$ & $40(9.4)$ & $18(8.7)$ \\
\hline Cystic fibrosis & $13(3.4)$ & $8(1.9)$ & $13(6.3)$ \\
\hline Urological disorders & $2(0.5)$ & $2(0.5)$ & 0 \\
\hline Outcomes & $\begin{array}{r}\text { Mean } \\
\text { (SD) }\end{array}$ & $\begin{array}{l}\text { Mean } \\
\text { (SD)b }\end{array}$ & $\begin{array}{l}\text { Mean } \\
\text { (SD)c }\end{array}$ \\
\hline $\begin{array}{l}\text { Independent Behaviors During Consultations Scale (IBDCS) } \\
\text { [range 7-35] }\end{array}$ & $2.4(0.8)$ & 2.6 & $3.3(1.0)^{\star *}$ \\
\hline General independence during consultations [range 1-10] & $7.6(1.8)$ & $7.8(1.8)^{*}$ & $8.0(1.5)^{\star \star}$ \\
\hline General Self-Efficacy Scale (GSES) [range 10-40] & $\begin{array}{c}30.0 \\
(4.5)\end{array}$ & $\begin{array}{c}30.9 \\
(5.2)^{*}\end{array}$ & $\begin{array}{l}32.2 \\
(5.0)^{* * *}\end{array}$ \\
\hline $\begin{array}{l}\text { On Your Own Feet Self-Efficacy Scale - knowledge (OYOF- } \\
\text { SES-A) [range 1-4] }\end{array}$ & $3.4(0.5)$ & $\begin{array}{l}3.5 \\
(0.5)^{* * *}\end{array}$ & $3.6(0.4)^{*}$ \\
\hline $\begin{array}{l}\text { On Your Own Feet Self-Efficacy Scale - skills for } \\
\text { consultations (OYOF-SES-B) [range 1-4] }\end{array}$ & $3.4(0.6)$ & $\begin{array}{l}3.5 \\
(0.5)^{* * *}\end{array}$ & $3.6(0.4)^{\star *}$ \\
\hline
\end{tabular}

aTwo teams did not participate in the questionnaire study; At T2, 9 teams from Round 3 did not participate.

bDifferences between T0-T1; paired samples T-test: $p$ value $\left.\left.\left.{ }^{*}\right) p<.05 ;{ }^{* *}\right) p<.01 ;{ }^{* * *}\right)$ $\mathrm{p}<.001$.

cDifferences between T1-T2; paired samples T-test: $p$ value *) $\left.\left.p<.05 ;{ }^{* *}\right) p<.01 ;{ }^{* * *}\right)$ $\mathrm{p}<.001$.

Table 6. Items related to independent behaviors during consultations (IBDCS)a and quality of current care (measured with 6 items of the Mind the GAP scale)b scored by adolescents

\begin{tabular}{|c|c|c|c|}
\hline During consultations in the hospital...a & \begin{tabular}{|l} 
T0 \\
$(\mathrm{n}=383)$ \\
mean \\
$(\mathrm{SD})$
\end{tabular} & \begin{tabular}{|l|}
$\mathrm{T} 1$ \\
$(\mathrm{n}=423)$ \\
mean \\
$(\mathrm{SD}) \mathrm{d}$ \\
\end{tabular} & \begin{tabular}{|l} 
T2 \\
$(\mathrm{n}=204)$ \\
mean \\
$(\mathrm{SD}) \mathrm{e}$
\end{tabular} \\
\hline I attend consultations on my own (without my parents) & $2.1(1.3)$ & $2.4(1.5)^{* * *}$ & $3.2(1.6)^{\star \star \star}$ \\
\hline I prepare for the consultation & $1.9(1.1)$ & $2.1(1.2)$ & $2.5(1.4)^{\star \star \star}$ \\
\hline I make the appointment myself & $1.9(1.3)$ & $2.2(1.4)^{\star \star \star}$ & $3.2(1.7)^{\star \star \star}$ \\
\hline I ask the doctor most of the questions myself & $2.6(1.2)$ & $2.8(1.4)$ & $3.4(1.3)^{\star \star \star}$ \\
\hline I answer most questions asked by my doctor myself & $3.3(1.3)$ & $3.3(1.5)$ & $4.3(1.0)^{\star * *}$ \\
\hline I discuss private matters with my doctor & $2.2(1.1)$ & $2.4(1.2)$ & $2.8(1.4)^{\star \star \star}$ \\
\hline I participate in decisions about my treatment & $3.0(1.4)$ & $3.2(1.5)^{*}$ & $3.8(1.2)^{\star \star \star}$ \\
\hline My current care...b & \begin{tabular}{|l} 
T0 \\
$(\mathrm{n}=378)$ \\
mean \\
$(\mathrm{SD})$
\end{tabular} & \begin{tabular}{|l|}
$\mathrm{T} 1$ \\
$(\mathrm{n}=408)$ \\
mean \\
$(\mathrm{SD}) \mathrm{d}$ \\
\end{tabular} & \begin{tabular}{|l} 
T2 \\
$(\mathrm{n}=198)$ \\
mean \\
$(\mathrm{SD}) \mathrm{e}$ \\
\end{tabular} \\
\hline \multicolumn{4}{|l|}{ (Related to Independent Consultations) } \\
\hline $\begin{array}{l}\text { a) Gives me opportunities to be seen in the clinic alone } \\
\text { (if I want to) }\end{array}$ & $5.4(1.9)$ & $5.7(1.8)^{* * *}$ & $6.2(1.1)^{\star *}$ \\
\hline $\begin{array}{l}\text { b) Allows me to decide who should be in the } \\
\text { consultation/examination room }\end{array}$ & $4.6(2.1)$ & $4.9(2.1)^{\star}$ & $5.9(1.3)^{\star * *}$ \\
\hline $\begin{array}{l}\text { Has staff who I can talk to about sensitive or difficult } \\
\text { issues }\end{array}$ & $4.8(2.0)$ & $5.0(2.0)$ & $5.3(1.5)^{\star *}$ \\
\hline \multicolumn{4}{|l|}{ (Related to Individual Transition Plans) } \\
\hline Helps me to prepare for my move to adult s & $4.3(1.9)$ & $4.5(2.1)$ & $5.0(1.7)^{\star \star}$ \\
\hline Helps me to plan for my future & $4.1(1.9)$ & $4.2(2.0)$ & $4.7(1.7)^{*}$ \\
\hline Helps me to improve independence by using an action & $4.0(2.0)$ & $4.0(2.0)$ & $4.4(1.8)^{*}$ \\
\hline
\end{tabular}


Staa, A. van, Sattoe, J.N.T., Strating, M.M.H. Experiences with and outcomes of two interventions to maximize engagement of chronically ill adolescents during hospital consultations: a mixed methods study. Journal of Pediatric Nursing: 2015, 30(5), 757-775

\begin{tabular}{|c|c|c|c|}
\hline During consultations in the hospital...a & $\begin{array}{l}\text { T0 } \\
(\mathrm{n}=383) \\
\text { mean } \\
(\mathrm{SD})\end{array}$ & \begin{tabular}{|l}
$\mathrm{T} 1$ \\
$(\mathrm{n}=423)$ \\
mean \\
$(\mathrm{SD}) \mathrm{d}$
\end{tabular} & $\begin{array}{l}\text { T2 } \\
(\mathrm{n}=204) \\
\text { mean } \\
(\mathrm{SD}) \mathrm{e}\end{array}$ \\
\hline planc & & & \\
\hline
\end{tabular}

aLikert 1 to 5 ; ranging from $1=$ never; to $5=$ always

bLikert 1 to 7 ; ranging from $1=$ strongly disagree; to 7 = strongly agree.

cSelf-constructed item (not included in the original Mind the GAP scale).

dDifferences between T0-T1 Wilcoxon Matched Pair Signed Rank test: $p$ value *) $p<.05 ;{ }^{* *}$ ) $\left.p<.01 ;{ }^{* * *}\right) p<.001$.

eDifferences between T1-T2 Wilcoxon Matched Pair Signed Rank test: $p$ value *) $p<.05 ;{ }^{*}$ ) $\left.p<.01 ;{ }^{* * *}\right) p<.001$.

Figure 5. Frequency of non-medical topics discussed during consultations.

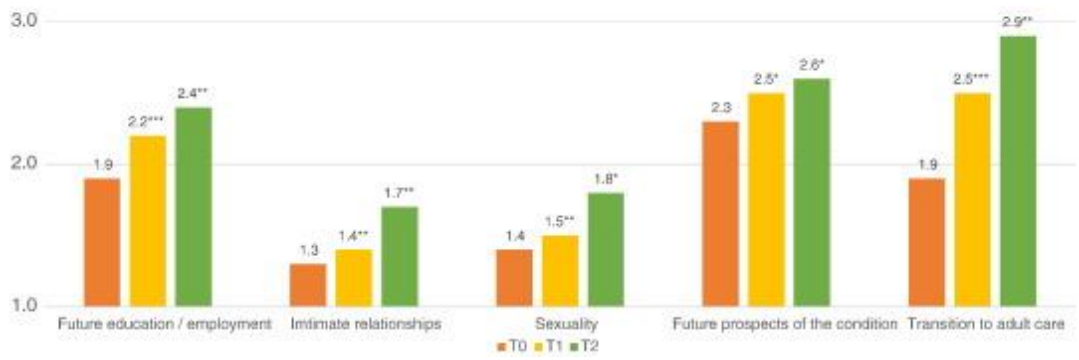

Figure 6. Importance of non-medical topics discussed during consultations.

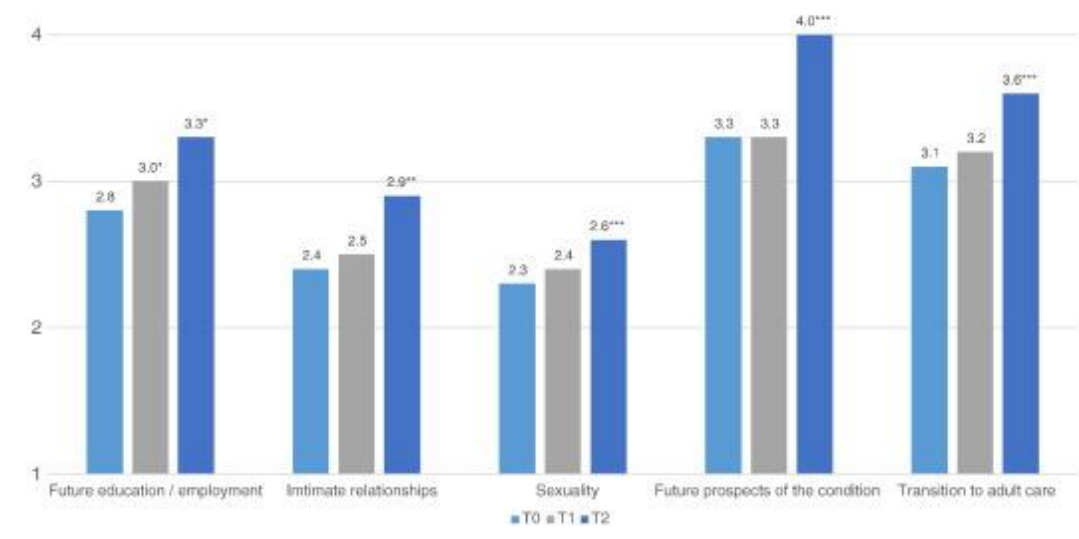

